$\begin{array}{llll}\text { Submission: } 17 / 04 / 2020 ; & 1^{\text {st }} \text { round notif.: 10/08/2020; } & \text { New version: 03/11/2020; } & 2^{\text {nd }} \text { round notif.: 27/02/2021; } \\ \text { Camera ready: } 15 / 03 / 2021 ; & \text { Edition review: 24/04/2021; } & \text { Available online: 01/05/2021; } & \text { Published: 01/05/2021; }\end{array}$

\title{
Apoiando a Comunicação Suplementar e Alternativa com Tecnologia Computacional Tangível em Storyboard
}

\section{Title: Supporting Augmentative and Alternative Communication with Tangible Computing Technology on Storyboard}

\author{
Eliana Alves Moreira \\ Instituto Federal de São Paulo \\ eliana.moreira@ifsp.edu.br
}

Maria do Carmo B. Bruschini Secr. Educação-Amparo, SP mcbbruschini@amparo.sp.gov.br

\section{E. Paula Cavalcanti}

Secr. Educação-Amparo, SP

epcavalcant@amparo.sp.gov.br

\author{
Eliane de S. Ramos \\ Secr. Educação - Amparo, SP \\ Fac. de Educação - UNICAMP \\ souzaramos80@gmail.com
}

Luciana Wolff

Secr. Educação - Amparo, SP

luwolff@uol.com.br

\section{Catia de T. Bortolini}

Secr. Educação-Amparo, SP

ccrtbortilini@amparo.sp.gov.br
Maria Luisa P. Benedetti

Secr. Educação-Amparo, SP

mlpbenedetti@amparo.sp.gov.br

Marisol R. P. de Oliveira

Secr. Educação-Amparo, SP

mrpoliveira@amparo.sp.gov.br

Leila A. D. Pinto

Secr. Educação-Amparo, SP

ladpinto@amparo.sp.gov.br
M. Cecília C. Baranauskas

Inst. de Computação - UNICAMP

cecilia@ic.unicamp.br

\section{Resumo}

A literatura acadêmica tem mostrado a importância do uso de tecnologias contemporâneas como auxílio em comunicação. Este trabalho propõe um sistema computacional para apoio à Comunicação Suplementar e Alternativa, usando interação tangível, na perspectiva do Design Universal. O desenvolvimento do sistema, alimentado por práticas participativas com profissionais de educação especial, tem permitido adequá-lo às necessidades dos estudantes que utilizam de tecnologia assistiva para se fazer comunicar nas salas de aulas inclusivas. A nova versão do sistema foi experimentada em estudo de caso com uma criança com necessidades complexas de comunicação. Resultados sugerem que o aluno demonstrou uma grande satisfação e motivação ao utilizar a nova versão do sistema. Desta forma, verifica-se que quando uma barreira é eliminada por meio de um sistema acessivel o resultado é visível, confirmando que a barreira/deficiência está no ambiente e não na pessoa. Ambientes acessíveis possibilitam que as pessoas usufruam do mesmo direito à comunicação. Vale ressaltar que o acesso à comunicação favorece o desenvolvimento cognitivo e a inserção social de todos. Resultados do estudo de caso também mostraram a importância de práticas participativas para a construção de novas tecnologias.

Palavras-Chave: Comunicação Suplementar e Alternativa; Interação computacional tangível; Ambiente educacional inclusivo; Práticas participativas.

\footnotetext{
Abstract

The academic literature has shown the importance of using contemporary technologies to support communication. This work proposes a computational system to support Augmentative and Alternative Communication by using tangible interaction, in the perspective of Universal Design. The development of the system, which was conducted by participatory practices with special education professionals, has allowed adaptations to meet the needs of students who use assistive technology to communicate in inclusive classrooms. The new version of the system was Cite as: Moreira, E. A., Ramos, E. S., Benedetti, M. L. P., Bruschini, M. C. B., Wolff, L., Oliveira, M. R. P., Cavalcanti, E. P., Bortolini, C. T., Pinto, L. A. D., \& Baranauskas, M. C. C. (2021). Supporting Augmentative and Alternative Communication with Tangible Computing Technology on Storyboard (Apoiando a Comunicação Suplementar e Alternativa com Tecnologia Computacional Tangivel em Storyboard). Brazilian Journal of Computers in Education (Revista Brasileira de Informática na Educação - RBIE), 29, 414-439. DOI: 
experimented in a case study with a child who has complex communication needs. This new version presented relevant and positive results, and the student showed great satisfaction and motivation when using the system. As the results are noticeable when a barrier is eliminated through an accessible system, it is confirmed that the barrier/deficiency is in the environment and not in the person. Therefore, accessible environments enable people to have the same rights to communication. In addition, it is important to highlight that the social insertion and the cognitive development of all people is benefited from the access to communication. Results of the case study also showed the importance of participatory practices for the construction of new technologies.

Keywords: Augmentative and Alternative Communication; Tangible computational interaction; Inclusive educational environment; Participatory practices.

\section{Introdução}

Em nossas pesquisas, temos realizado atividades que se pautam na perspectiva do design para todos, como abordagem ao Design Universal (Casa Civil, 2009; Story, Mueller, \& Mace, 1998). Com estas pesquisas, buscamos possibilitar a construção e a avaliação incrementais de um ambiente tecnológico que utiliza interação tangível como suplemento à comunicação dos alunos com seus colegas e professores, principalmente aqueles que apresentam necessidades complexas de comunicação, matriculados em escolas comuns. Consideramos que uma escola comum e regular é aquela que não coloca condições para realizar a matrícula e oferecer uma educação de qualidade, acessível e inclusiva, a todos e todas. Para Mantoan (2003, p. 22), "a exclusão escolar manifesta-se das mais diversas e perversas maneiras, e quase sempre o que está em jogo é a ignorância do aluno diante dos padrões de cientificidade do saber escolar". Já as escolas especiais, ocupam espaços segregados na sociedade e trabalham exclusivamente com alunos que têm uma deficiência. Elas são regulares, mas não são comuns. Embora existam escolas especiais no Brasil, elas não podem oferecer uma educação inclusiva dada a sua natureza excludente.

Os alunos que são foco deste trabalho, frequentam o Atendimento Educacional Especializado (AEE), que é um serviço da Educação Especial voltado à eliminação das barreiras que possam obstruir o processo de formação escolar e cidadã de estudantes considerados com deficiência, altas habilidades ou superdotação e transtornos globais do desenvolvimento (Casa Civil, 2011; Ministério da Educação, 2007). A oferta desse serviço ao seu público-alvo é obrigatória, porém, ele não pode substituir, em hipótese alguma, as atividades que são realizadas no ensino comum.

Neste trabalho, denominamos "tecnologias computacionais contemporâneas" àquelas que possibilitam outras formas de interação e comunicação (via dispositivos no ambiente, em objetos concretos, por exemplo, sensores, atuadores etc.) que vão além das tecnologias e dispositivos tradicionais (teclado, mouse, monitor). Segundo Ullmer e Ishii (2000), as tecnologias de interfaces tangíveis, que dão forma física à informação digital, empregam artefatos físicos que, quando manipulados, funcionam como representações e controles para mídia computacional, proporcionando uma interação mais direta do usuário com o sistema, via elementos concretos (do cotidiano, por exemplo). As interfaces tangíveis associam representações físicas com representações digitais, produzindo sistemas interativos que são computacionalmente mediados, mas geralmente não são identificados como "computadores" per se (Ullmer \& Ishii, 2000). O propósito de trabalhar com ambiente baseado em tecnologias tangíveis se justifica pelo fato de que o usuário pode interagir com o sistema de forma mais natural, quando comparado ao uso de dispositivos tradicionais de interação. Ainda, o uso de materiais tangíveis estimula múltiplos sentidos, o desenvolvimento de funções cognitivas e habilidades de percepção que envolvem diferentes partes do corpo (Garzotto \& Bordogna, 2010).

Quando um aluno fala e o seu interlocutor não entende o que ele quer comunicar, ou ainda, quando um aluno não fala, é preciso criar alternativas que possibilitem uma interação, no ambiente escolar e fora dele, sem barreiras de comunicação. Na literatura científica, esses alunos têm sido considerados como aqueles que têm necessidades complexas de comunicação. Nesse sentido, um 
conjunto de ferramentas e estratégias que o aluno, bem como seus colegas e professores podem utilizar enquanto se comunicam, é a Comunicação Suplementar e Alternativa (CSA) ${ }^{1}$, que funciona como complemento e/ou substituição da fala, a fim de que se amplie as possibilidades de interação e de comunicação (ASHA, 2016). O conjunto de componentes da CSA envolve sistemas manuais (gestos, alfabeto digital, o português sinalizado, além de outros marcadores gramaticais complexos) e gráficos, tais como fotos, desenhos de alta iconicidade, símbolos gráficos e a ortografia tradicional (Sonza et al., 2013). Símbolos gráficos podem ser organizados em bibliotecas, como por exemplo, o Picture Communication Symbols (PCS) (Mayer-Johnson Inc., 2002) e o Arasaac (ARASAAC, 2018).

Este artigo estende um trabalho anterior (Moreira et al., 2018), em que compartilhamos nossa experiência no estudo da extensão de um ambiente computacional tangível de apoio à comunicação, para trabalhar com narrativas, que foi construído com base nas sugestões e resultados do uso da versão inicial (Moreira \& Baranauskas, 2016). Dentro de uma abordagem metodológica baseada no Design Participativo (Kensing \& Blomberg, 1998), contamos com a participação de professoras que realizam o AEE e têm experiência no trabalho com alunos que apresentam necessidades complexas de comunicação. As ideias descritas no artigo refletem as maneiras como essas professoras propuseram o uso do ambiente, visando aspectos da CSA e do Design Universal subjacentes ao trabalho com narrativas. Este artigo contribui com a apresentação e discussão de uma nova iteração no desenvolvimento do sistema de software. Ao longo deste texto, ilustramos o uso da nova versão do sistema com uma criança com necessidades complexas de comunicação.

Nas próximas seções apresentaremos trabalhos relacionados, o contexto da pesquisa e o ambiente utilizado, a metodologia de Oficinas Participativas, do design da funcionalidade de narrativas com propostas para sua aplicação, o desenvolvimento de uma segunda versão do sistema e uma aplicação prática de uso com uma criança. Por fim, concluímos, sintetizando as contribuições deste artigo e apontando para novas possibilidades de pesquisa.

\section{Trabalhos Relacionados}

Em contextos dos quais são parte crianças que se comunicam por meio de sistemas alternativos, Tenor e Deliberato (2004) realizaram um estudo sobre estratégias de mediação para o conto e reconto de histórias com alunos que têm surdez. Segundo essas autoras, os estudos evidenciaram a necessidade de apoiar esses alunos na construção de habilidades narrativas. Elas destacaram que a história "estimula a imaginação, educa, instrui, desenvolve habilidades cognitivas, dinamiza o processo de leitura e escrita, além de ser uma atividade interativa que potencializa a linguagem infantil" (p. 683). Ainda de acordo com as autoras, sistemas visuais (gráficos) "colaboram na produção da narrativa e poderiam ser um instrumento favorecedor para aquisição da narrativa de alunos com surdez, em função dos marcadores visuais oferecidos para as questões de sentido e de organização do pensamento" (p. 684), o que certamente podemos estender para pessoas em situação de deficiência, que são mais bem atendidas quando contam com recursos que tornam os ambientes acessíveis.

Pesquisadores têm estudado sistemas gráficos e narrativas a partir de tecnologias tangíveis.

Garzotto e Bordogna (2010) propuseram o Talking Paper, um ambiente que possui uma abordagem para associar conteúdos visuais físicos com recursos multimídia. Na proposta desses

\footnotetext{
1 No Brasil, entre as diversas áreas de estudo, não existe um consenso sobre termos para Augmentative and Alternative Communication, originário do inglês, sendo comum encontrar, os termos Comunicação Aumentativa e Alternativa, Comunicação Alternativa e Ampliada, entre outros (Chun, 2009).
} 
autores, elementos baseados em papéis são equipados com tecnologia de etiquetas de Radio Frequency Identification (RFID). Essas etiquetas se conectam aos recursos multimídia, tais como controles multimídia de comportamento, vídeos, música e voz, de modo a organizar uma narrativa de uma história conhecida (ao juntar cenas para formar um todo em uma ordem significativa), e construir associações entre o componente da história e os símbolos de CSA correspondentes. No ambiente do Talking Paper, o participante utiliza papéis com cenas de uma história pré-definida, conectados a um vídeo dessa mesma cena, limitando sua utilização aos papéis e vídeos já criados.

Hengeveld, Hummels, Balkom, Voort, e Moor (2013) projetaram um sistema modular, denominado Linguabytes, composto de materiais lúdicos para leitura de histórias interativas e exercícios linguísticos para crianças com dificuldades na comunicação, acompanhadas de seus cuidadores ou responsáveis. O protótipo consiste em módulos para entrada, saída e controle, juntamente com materiais tangíveis para entrada, palavras e etiquetas RFID programáveis para histórias e exercícios. Apresenta também fundos temáticos tangíveis que devem ser inseridos no módulo base para pré-carregar as histórias, jogos e exercícios. Por ser um ambiente composto por módulos físicos construídos a partir de sensores e atuadores, a sua replicação é dificultada.

Panday e Swati (2011) propuseram o Tiblo, que se refere a blocos interativos tangíveis e funciona como um auxílio tangível de aprendizagem para crianças com dislexia na faixa etária de 8 a 12 anos. Tiblo é composto por blocos eletrônicos interativos modulares; cada um deles pode gravar e reproduzir até dez segundos de som pré-gravado e, devido à sua forma, pode se conectar fisicamente a outros blocos semelhantes em qualquer orientação. Possui uma pequena placa de pin-up em sua superfície para fixar figuras (desenhos) criadas pelas crianças.

Alessandrini, Cappelletti e Zancanaro (2014) apresentam uma ferramenta computacional tangível para trabalhar com crianças com autismo, que permite ao usuário atribuir sons a folhas de papel. Esse recurso tem como objetivo motivar a criança para a atividade de contar histórias. As folhas de papel podem ter desenhos criados por crianças, imagens ou fotos. O protótipo final é baseado em uma luminária de mesa com uma câmera no lugar da lâmpada, usada para "ver" marcadores fiduciais (imagens com algumas propriedades específicas que facilitam seu reconhecimento automático). Um laptop, conectado à luminária através de uma porta USB, executa um programa que realiza a gravação, armazenamento e reprodução dos arquivos de áudio e outras operações relacionadas.

Baranauskas e Gutierrez (2017) propuseram um ambiente computacional, denominado CPES, baseado em interfaces tangíveis (com marcadores fiduciais e cartões RFID), desenhado para todos, com o objetivo de permitir a um grupo de crianças e professores, criar, compartilhar e contar histórias juntos. A construção da narrativa no CPES envolve três etapas principais. Na primeira etapa, os parceiros se reúnem para definir os diferentes elementos da história e um plano para ela. Na segunda etapa, os parceiros criam todos os elementos da história usando os recursos físicos disponíveis (por exemplo, brinquedos, desenhos etc.) e os elementos CPES para criar a história. Por fim, na última etapa, a história é contada para o público com o uso dos recursos do CPES. Durante este processo de contar a história, os contadores e o público podem gerar interações no sistema motivados por algum comportamento (por exemplo, aplausos), provocando a execução de comandos programados pelos próprios usuários no CPES.

Os trabalhos relacionados apresentados anteriormente, embora não sejam exaustivos desta classe de sistema de comunicação baseado em tecnologia, mostram o uso de interfaces tangíveis para trabalhar narrativas com crianças consideradas com deficiência. Os trabalhos previamente apresentados (com exceção do último) são projetados para atender a deficiência entendida como algo exclusivo do aluno. Diferentemente dessas propostas, o ambiente que criamos não foi projetado para atender as especificidades de uma "deficiência específica". Nosso foco neste trabalho de pesquisa está voltado para a abordagem do Design Universal, pois outras pessoas envolvidas no ambiente em que esses alunos estão inseridos também podem se beneficiar com o 
uso de tais recursos. Para nós, é preciso que a deficiência seja reconhecida nas situações inacessíveis que têm levado a sociedade a fixar injustamente nos alunos, a deficiência pertencente ao meio. Ainda, entendemos que a cultura e as particularidades nos modos como se concebe e pratica o ensino, em diferentes países, devem ser consideradas durante o desenvolvimento de ferramentas que visem eliminar barreiras na comunicação em escolas inclusivas.

Acreditamos que a tecnologia computacional projetada, apresentada neste artigo, pode ser concebida como um recurso que tem grande potencial para eliminar barreiras comunicacionais que se localizam entre diferentes interlocutores. Destes interlocutores, destacamos aqueles considerados com necessidades complexas de comunicação. O ambiente que propomos é composto por cartões com símbolos gráficos de CSA, criados previamente e de acordo com o estudo dos casos de alunos que os utilizarão, que podem ser combinados para trabalhar com narrativas, sem que devam corresponder à lógica de uma história pré-definida. Ainda, nosso ambiente computacional é composto pelo uso de cartões e leitor RFID, que são de baixo custo e altamente acessíveis no mercado, além do sistema computacional de base gerencial, que possibilita a reutilização dos cartões.

\section{Contexto da Pesquisa}

Em nossos estudos, realizamos Oficinas ${ }^{2}$ Participativas (Baranauskas, 2013) ao longo de vários semestres, em colaboração com um espaço educativo (cenário 1), denominado Divisão de Educação Infantil e Complementar - DEdIC ${ }^{3}$, que funciona dentro da Universidade Estadual de Campinas (UNICAMP), na unidade do Programa de Desenvolvimento e Integração da Criança e do Adolescente - Prodecad, oferecendo educação complementar a crianças de 6 a 14 anos, em horário de contraturno ao ensino regular e comum. Outra parceria (cenário 2) é a rede municipal de ensino de Amparo, estado de São Paulo, mais especificamente escolas onde existem Salas de Recursos Multifuncionais, que são ambientes dotados de equipamentos, mobiliários e materiais didáticos e pedagógicos para a oferta do AEE (Casa Civil, 2011). Esta rede atende crianças da Educação Infantil, Ensino Fundamental I e Educação de Jovens e Adultos (EJA).

Nas Oficinas Participativas do cenário 2, conhecimentos da Computação e da Educação se encontraram, articularam e renovaram. Nos encontros, os ciclos de design se formalizaram e tornaram cada vez mais exequível a produção de um recurso tangível voltado à comunicação. As Oficinas Participativas, que aconteceram em uma dinâmica dialogada e por meio de técnicas de Braindraw, romperam com a hierarquização de saberes e áreas do conhecimento, conforme todos foram acolhidos e considerados em suas indagações e contribuições. As produções dessas Oficinas foram reunidas pela pesquisadora e o trabalho colaborativo foi nutrido com conhecimentos da Computação. Além disso, protótipos computacionais foram produzidos e frequentemente analisados por todas as professoras da equipe, até que pesquisadora e professoras chegaram a uma versão final do recurso. Durante as Oficinas, as professoras do AEE compartilharam as barreiras comunicacionais que identificavam e pretendiam eliminar no trabalho com alunos que apresentavam necessidades complexas de comunicação. Elas construíram relações entre as possibilidades computacionais tangíveis apresentadas e as barreiras comunicacionais com as quais trabalhavam cotidianamente na escola.

As professoras de AEE, na ocasião deste estudo, já realizavam estudos de caso nos quais identificavam as barreiras comunicacionais que impedem alunos, professores, funcionários da escola e familiares, de interagir e comunicar. No AEE, as professoras de educação especial, quando trabalham com alunos considerados com necessidades complexas de comunicação,

\footnotetext{
${ }^{2}$ Projeto aprovado pelo Comitê de Ética em Pesquisa (UNICAMP), sob número 55678316.4.0000.5404.

${ }^{3} \mathrm{http}: / /$ www.dgrh.unicamp.br/dedic
} 
selecionam, em parceria com alunos, professores e familiares, símbolos que compõem pranchas de CSA. Feito isso, elas organizam situações de comunicação nas quais tais pranchas passam a ser utilizadas de maneira espontânea, conforme cada aluno e seus interlocutores interagem. As pranchas vão sendo atualizadas quando deixam de contemplar as necessidades de interação e comunicação de cada estudante. A Figura 1 contém dois exemplos de sistemas gráficos preparados (e personalizados) para alunos que frequentam as Salas de Recursos Multifuncionais da rede municipal de ensino parceira. As pranchas de comunicação ilustradas na figura são o resultado do estudo de caso feito pelas professoras de AEE (participantes do trabalho que apresentamos neste artigo) e serviram como base para o desenvolvimento dos objetos tangíveis computacionais utilizados no sistema relatado ao longo do texto. Para produzir as pranchas de comunicação com símbolos gráficos, tais professoras dispõem do sistema computacional BoardMaker, que utiliza o sistema gráfico PCS (Mayer-Johnson Inc., 2002), e contam com a assessoria de uma fonoaudióloga doutora na área.
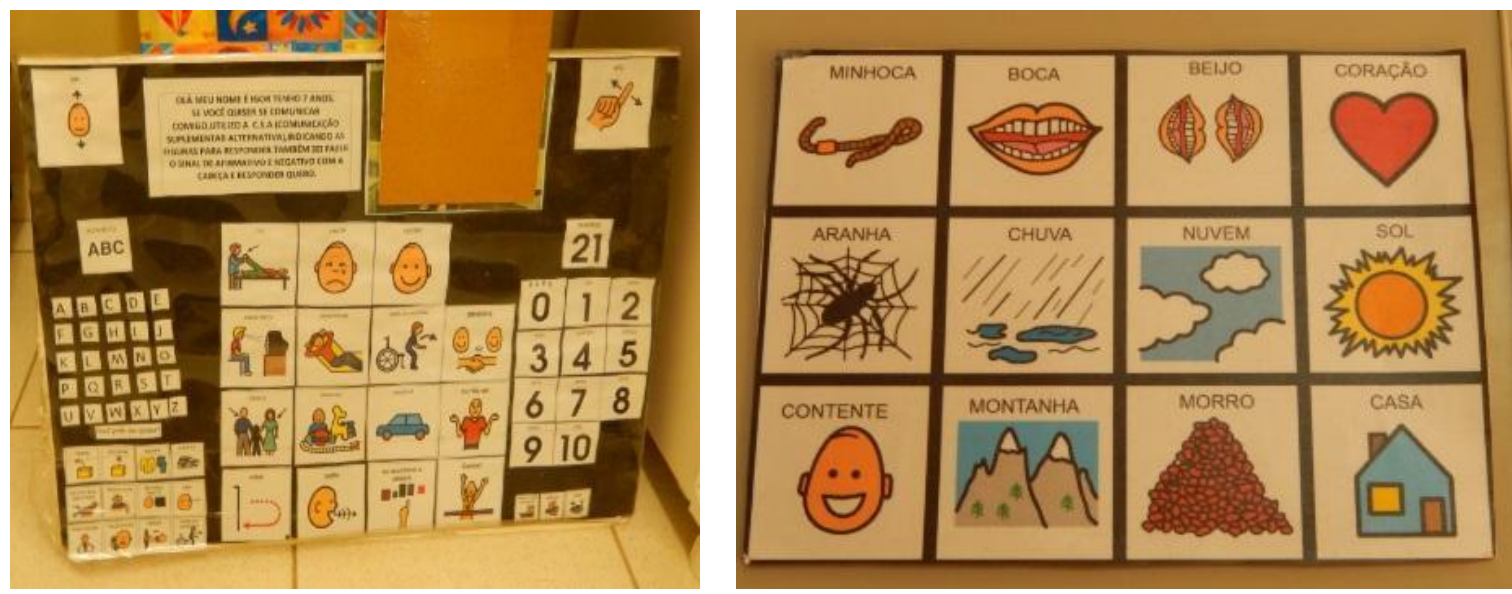

Figura 1. Fotos de sistemas gráficos de CSA utilizados nas Salas de Recursos Multifuncionais da rede de ensino parceira, produzidas através da aplicação BoardMaker (Mayer-Johnson Inc., 2002).

\subsection{O ambiente computacional tangível na comunicação}

O ambiente proposto para situações de comunicação utiliza tecnologia tangível com etiquetas RFID. A possibilidade de criar diferentes discursos, bem como a ludicidade no uso dos cartões, contribuem para que a comunicação entre os usuários do ambiente seja criativa, espontânea e alcance a maior extensão possível de usuários (Moreira \& Baranauskas, 2016).

O ambiente tecnológico é composto por cartões com etiquetas RFID de $13.56 \mathrm{MHz}$, um leitor RFID compatível, um computador, saídas de som e de imagem, conforme ilustram a Figura 2 e a Figura 3a.

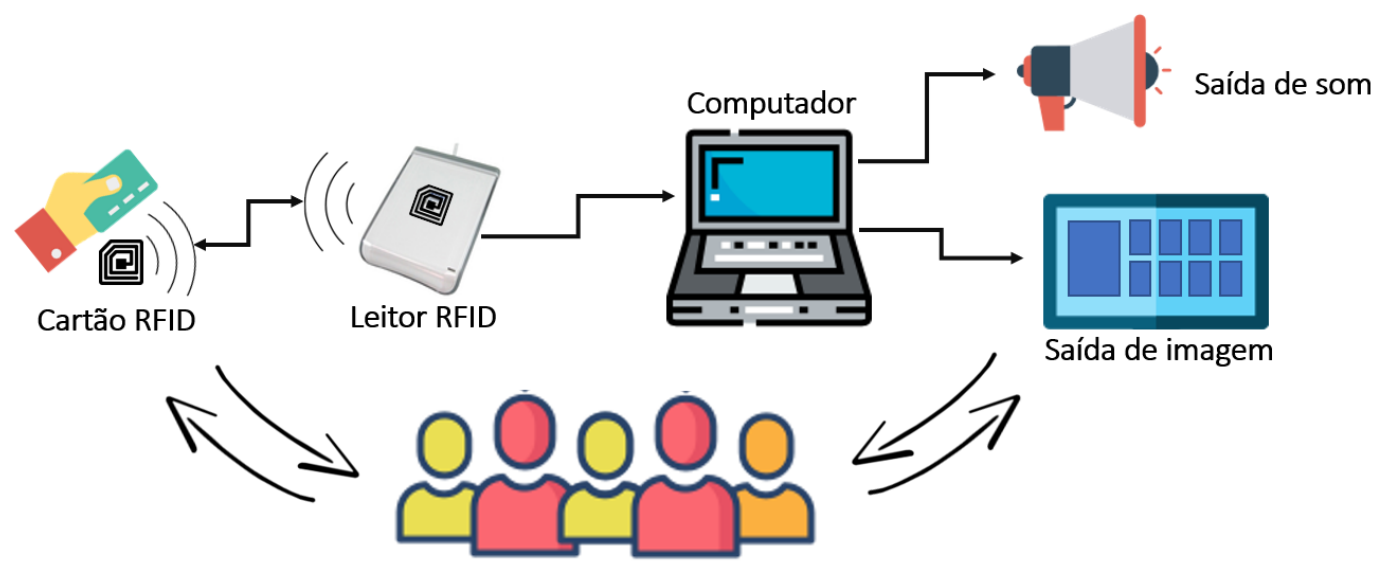

Figura 2. Visão geral do ambiente tecnológico. 
Entre os componentes do ambiente estão conjuntos de cartões com figuras pictográficas, disponibilizadas pelo Centro Aragonês de Comunicação Aumentativa e Alternativa (ARASAAC, $2018)^{4}$. Cada cartão contém a representação da figura em Língua Portuguesa e, em seu verso, no Sistema de Escrita Braille, (Figura 3b). Possui ainda uma vocalização associada, ativada quando o cartão é lido por um leitor de RFID compatível. A criação dos cartões baseou-se em visitas às Salas de Recursos Multifuncionais da rede de ensino parceira e em revisões da literatura. Nessas observações foi possível verificar que a utilização de figuras pictográficas é um recurso costumeiramente utilizado em ações, oriundas da educação especial, que pretendem eliminar barreiras de comunicação.

O ambiente original possui 188 "Cartões de Comunicação" (Figura 3b) e 22 "Cartões de Eventos" (Figura 3c), estes últimos utilizados para controlar ações gerenciais do software. Os cartões de comunicação são organizados por categorias, tais como "Alimentos", "Animais", "Lugares", "Personagens", entre outras, diferenciadas pela cor da borda dos cartões e por códigos únicos que neles são impressos (e.g. "P-1" no cartão ilustrado na Figura 3b). Ainda, existe o conceito de conjuntos, que representam maneiras distintas de agrupar os cartões criados (por exemplo, conjunto de cartões com fotos, com símbolos gráficos etc.).

(a)

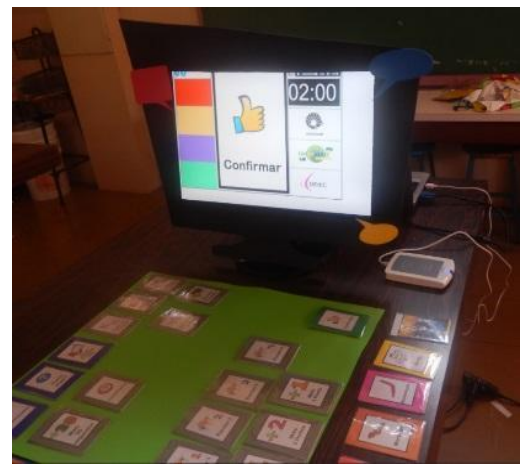

(b)

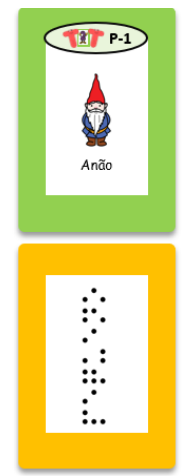

(c)

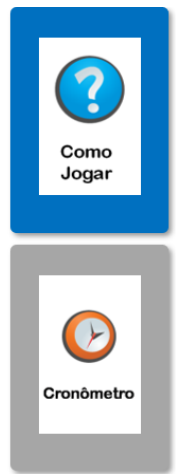

(d)



Figura 3. (a) Ambiente computacional tangível de apoio à comunicação (em execução, o Modo de Jogo); (b) exemplos de cartões de comunicação e de eventos, com figuras extraídas de ARASAAC (2018), e representação no Sistema de Escrita Braille no verso; (c) exemplo de cartão-tema.

O ambiente foi concebido inicialmente para ser utilizado em um Modo de Jogo (no caso, de adivinhações, c.f. Figura 3a), onde um participante sorteia um tema e então apresenta, por meio do ambiente, os cartões de comunicação que julga representativos para comunicar o tema sorteado, que deve ser "adivinhado" pelos demais participantes do jogo. Para apoiar o jogo de adivinhações, o ambiente conta, originalmente, com dois grupos-tema: "Animações" e "Cotidiano", compostos por 56 e 21 temas, respectivamente. Como exemplos de temas de "Animações" temos: "Super-Homem" e "Chapeuzinho Vermelho". Como exemplos de temas de "Cotidiano" temos: "Escovar os dentes após as refeições" e "Conversar com os amigos" (Figura 3d). Cada um desses temas possui uma representação (imagem) associada a um cartão RFID.

A quantidade original de cartões de comunicação foi baseada em uma quantidade finita de símbolos que foram propostos pelos desenvolvedores do ambiente para representar os temas. Esse "vocabulário" original foi avaliado e validado pelas professoras e alunos em um estudo feito no cenário 1 (Moreira \& Baranauskas, 2018). A quantidade original de cartões de eventos está diretamente relacionada aos eventos criados para controlar o jogo de adivinhações e às ações gerenciais da versão 1.0 do Modo de Storyboard (descrito na Seção 4).

\footnotetext{
${ }^{4}$ Os símbolos pictográficos usados são propriedade do Governo de Aragão e foram criados por Sérgio Palao para ARASAAC (www.arasaac.org), que os distribui sob uma Licença Creative Commons BY-NC-SA.
} 
A professora de AEE, a partir do estudo de caso do aluno com necessidades complexas de comunicação, define o número de cartões, o conteúdo que será representado nos mesmos e quais serão utilizados por/com ele. O uso efetivo deste material, especialmente na escola e na família, orienta a inserção e a retirada de novos cartões das pranchas de cada aluno. Para atender a essa condição, o ambiente computacional permite a criação e customização de novos cartões de comunicação ou de eventos, por meio do Modo de Gerenciamento.

Para que o ambiente funcione de maneira satisfatória, é necessário que se siga corretamente o fluxo de como os dados devem ser persistidos e utilizados. Por exemplo, para cadastrar um "Cartão de Comunicação", é necessário haver cadastrado o conjunto e a categoria aos quais o cartão pertencerá. O diagrama de dependência da Figura 4 contém uma representação da ordem desse fluxo de dados (observe que a origem da seta ocorre na funcionalidade dependente).

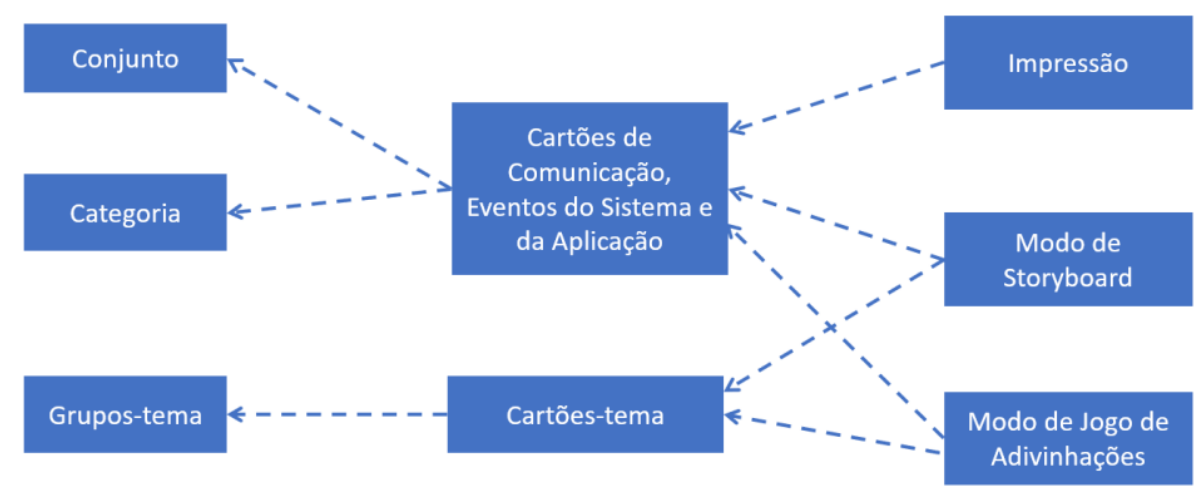

Figura 4. Fluxo de dados para criação e utilização dos cartões no ambiente.

\subsection{Oficinas participativas em espaço de educação complementar (cenário 1)}

Em um primeiro momento de nossas pesquisas, realizamos diversas Oficinas com o ambiente (sistema computacional, display e objetos tangíveis com tecnologia embutida) em espaço de educação complementar. Nessas Oficinas trabalhamos com professoras e crianças (Figura 5), utilizando o Modo de Jogo do ambiente; nenhuma pessoa encontrava dificuldades para se fazer entender pela oralidade. Entretanto, realizamos adicionalmente Oficinas para verificar a eficácia do vocabulário proposto no ambiente, focando no seu potencial para ampliar a situação de comunicação quando diferentes pessoas interagem com temáticas específicas (Moreira \& Baranauskas, 2018).

Os resultados dessas Oficinas foram apresentados anteriormente (Moreira \& Baranauskas, 2016), contudo destacamos a seguir alguns deles. Percebemos que seria importante fornecer alternativas para quando o participante possuísse uma limitação que o impedisse de enxergar os conteúdos dos cartões durante a sua utilização, ainda que projetássemos o símbolo gráfico e a vocalização da palavra referente à figura. As figuras estavam agrupadas por categoria, porém algumas crianças não estavam familiarizadas com a classificação dos conteúdos, sendo então necessária a criação de uma estratégia para busca pelas figuras de forma otimizada. Tal estratégia foi a diminuição do número de cartões, o que ocasionava na diminuição do vocabulário para se expressar determinadas informações; em contrapartida, exigia mais o uso de associação de ideias pelos interlocutores. Os resultados culminaram em um redesenho do ambiente, para estender a comunicação a um maior número de pessoas. 



Figura 5. Ofícinas realizadas com professoras e crianças (cenário 1).

Este trabalho detalha, nas próximas seções, os acontecimentos de Oficinas ocorridas no cenário 2, onde professoras de educação especial utilizaram o ambiente já redesenhado de acordo com as sugestões realizadas nas Oficinas do cenário 1.

\subsection{Oficinas participativas com professoras de educação especial que realizam o AEE (cenário 2)}

Com o ambiente redesenhado, demos continuidade às nossas pesquisas, realizando um segundo conjunto de Oficinas, que aconteceu junto ao Programa de Educação Inclusiva da rede municipal de ensino parceira (Amparo, 2016). As participantes utilizaram o ambiente já redesenhado de acordo com as sugestões realizadas nas Oficinas do cenário 1.

No cenário 2, conduzimos Oficinas com cinco professoras de educação especial que realizam o AEE com alunos considerados com necessidades complexas de comunicação, uma coordenadora de educação especial, além de duas assessoras (uma professora de Libras, fonoaudióloga e doutora em Educação e a outra especialista em CSA, com formação em fonoaudiologia e doutora na área). A Tabela 1 apresenta um resumo da formação e do tempo de atuação de cada umas das profissionais participantes da rede parceira.

A Figura 6 apresenta uma visão geral de como as Oficinas influenciaram o design e redesign incremental do ambiente descrito neste artigo. A seta circular representa o redesign do ambiente e em seu interior está o parceiro que participou das oficinas que influenciaram esse redesign. A seta reta representa uma evolução do sistema, seja em uma nova funcionalidade ou uma nova plataforma de uso. 
Tabela 1. Formação e tempo de atuação das participantes das Oficinas ocorridas no cenário 2.

\begin{tabular}{|c|c|c|}
\hline Participante & Formação & $\begin{array}{c}\text { Tempo de atuação em } \\
\text { educação especial }\end{array}$ \\
\hline Professora & $\begin{array}{l}\text { Pós-graduação em AEE } \\
\text { Psicopedagogia Construtivista }\end{array}$ & 6 anos \\
\hline Professora & $\begin{array}{l}\text { Pós-graduação em Educação Especial } \\
\text { Pós-graduação em Libras }\end{array}$ & 12 anos \\
\hline Professora & 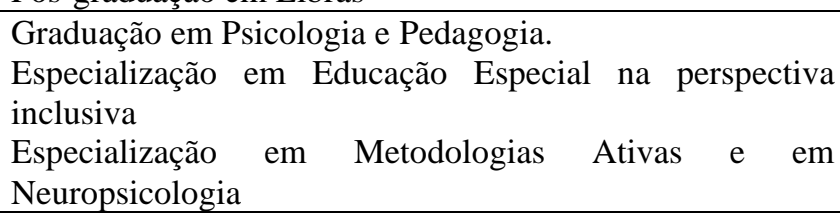 & 6 anos \\
\hline Professora & $\begin{array}{l}\text { Graduação em Pedagogia Plena } \\
\text { Pós-graduação em Educação Inclusiva com ênfase em } \\
\text { Deficiência Intelectual }\end{array}$ & 12 anos \\
\hline Professora & $\begin{array}{l}\text { Psicopedagoga Construtivista } \\
\text { Pós-graduação em Educação Inclusiva } \\
\text { Pós-graduação em Supervisão Escolar } \\
\text { Pós-graduação em Educação Especial e AEE } \\
\text { Pós-graduação em Metodologias Ativas e intermeio do } \\
\text { Ensino Superior } \\
\text { Pós-graduação em Estratégias pedagógicas para o aluno } \\
\text { com deficiência mental } \\
\text { Formação na Língua Brasileira de Sinais }\end{array}$ & 8 anos \\
\hline $\begin{array}{l}\text { Coordenadora de } \\
\text { educação especial }\end{array}$ & $\begin{array}{l}\text { Graduação em Pedagogia } \\
\text { Pós-graduação em Psicopedagogia Construtivista }\end{array}$ & 8 anos \\
\hline Assessora & $\begin{array}{l}\text { Professora } \\
\text { Fonoaudióloga } \\
\text { Mestrado e doutorado em Educação } \\
\text { Docente no ensino superior. Assessora em escolas públicas } \\
\text { e privadas na construção de uma escola para todos. } \\
\text { Desenvolve pesquisas sobre: inclusão escolar no ensino } \\
\text { comum e na educação especial, tecnologia assistiva e } \\
\text { educação bilíngue (Língua Portuguesa e Libras). }\end{array}$ & 15 anos \\
\hline Assessora & Graduação, mestrado e doutorado em fonoaudiologia & 28 anos \\
\hline
\end{tabular}

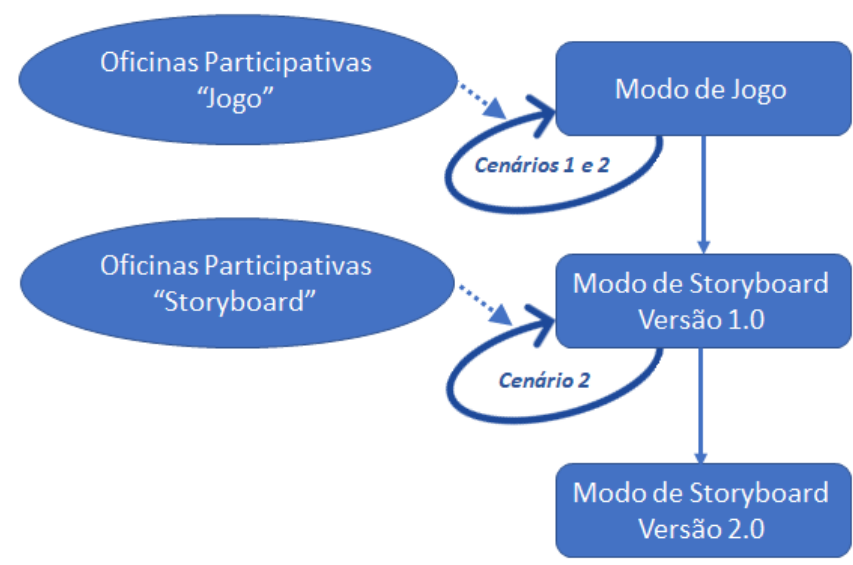

Figura 6. Visão geral do design e redesign do ambiente proposto para situações de comunicação.

Foram realizadas duas Oficinas de duas horas cada, com momentos retratados na Figura 7. 

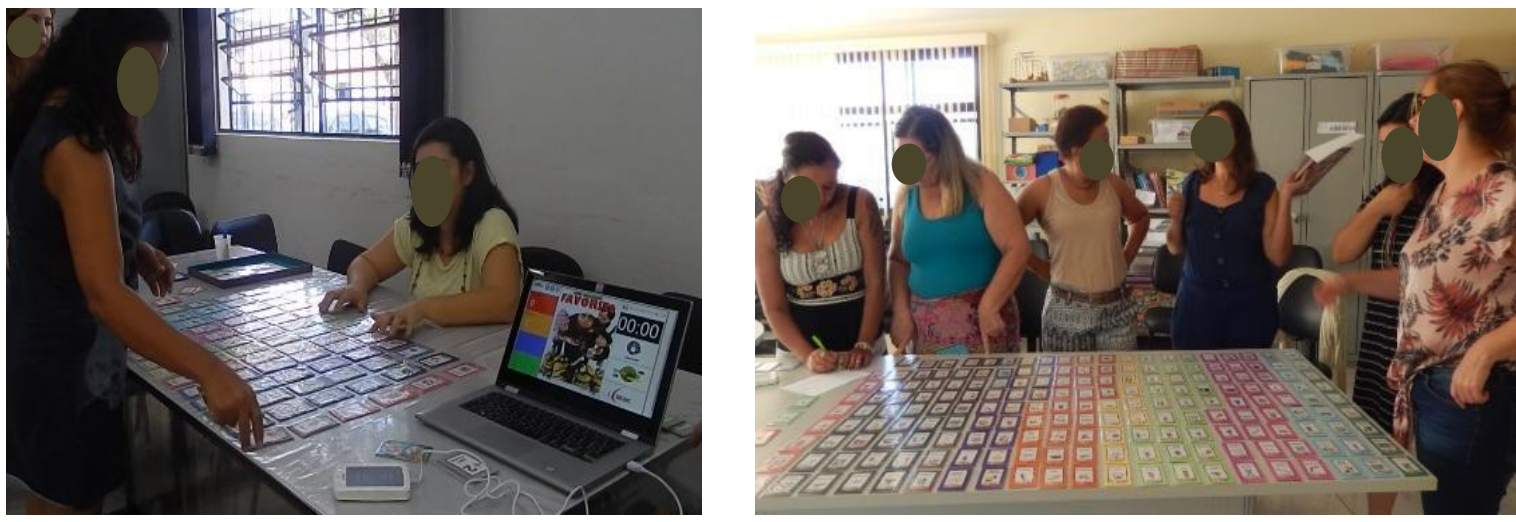

Figura 7. Momentos de Oficinas com professoras de educação especial que realizam o AEE: à esquerda, "Oficina Jogo"; à direita, "Oficina Storyboard".

Na primeira Oficina, que chamamos de "Oficina Jogo", as participantes utilizaram o ambiente computacional tangível para apoio à comunicação sob a forma de jogo de adivinhações, modo como foi inicialmente desenvolvido e experimentado no cenário 1. Após o jogo, as participantes fizeram uma avaliação, utilizando um questionário com questões abertas, onde apresentaram sugestões de usos de recursos de CSA no ambiente, tendo como base as atividades que elas desenvolvem com as crianças no AEE. Analisando as respostas do questionário, identificamos que elas reconheceram no sistema computacional proposto um potencial para eliminar barreiras na comunicação durante o trabalho com alunos considerados com necessidades complexas de comunicação e seus colegas de turma. Contudo elas sugeriram a criação de uma funcionalidade que fosse mais abrangente no trabalho com os estudantes, de acordo com cada caso. As professoras ressaltaram que um sistema computacional com esta finalidade deve tornar possível a expressão de sentimentos, preferências, opiniões, questionamentos, conteúdos escolares, entre outros. Ainda, elas enfatizaram que ao se sentir contemplado em suas necessidades comunicacionais, um aluno passa a participar efetivamente das atividades pedagógicas e educacionais realizadas no ensino comum. Estas atividades podem proporcionar $o$ desenvolvimento da linguagem, da criatividade, do intelecto, de noções temporais e espaciais, de regras e convenções sociais, além de oportunizar a gestão de conquistas e frustrações que são próprias da convivência com pares cronológicos e adultos.

Diante desse contexto e considerando a nossa proposta de desenvolvimento incremental do ambiente, fizemos um estudo para definir qual seria a melhor forma de modificá-lo de modo a atender às sugestões das participantes. Os detalhes desse estudo, bem como a segunda Oficina, que denominamos de "Oficina Storyboard", onde aplicamos as modificações realizadas, estão descritos a seguir.

\section{Design do Modo de Storyboard}

Idealizamos o Modo de Storyboard de modo a adequar o ambiente computacional tangível para apoio a comunicação às sugestões que as professoras de educação especial que realizam o AEE haviam feito na "Oficina Jogo".

Os storyboards são representações pictóricas de histórias, geralmente realizadas com as próprias palavras do locutor (Burton \& Matthewson, 2015), funcionando como um guia visual, em forma de quadros. O storyboard exprime as principais cenas de um produto audiovisual de forma rápida e objetiva, uma espécie de "história em quadrinhos" que retrata o conteúdo de um material, na maioria das vezes, audiovisual. Porém, é utilizado também para ilustrar sequências de conteúdos em disciplinas escolares, momentos de interação de um usuário com um sistema, entre outros. Geralmente, uma imagem de um storyboard precisa retratar a essência do que se 
quer comunicar, sem, no entanto, determinar muitos detalhes, sendo importante mostrar a sequência e clima de uma cena.

No nosso sistema, a intenção ao utilizar o storyboard é oferecer uma forma de organizar ideias de modo a trabalhar narrativas com estudantes dentro do tema proposto pelas professoras. Para isso propusemos uma forma de apresentação, onde uma cena é composta por vários quadros do storyboard, cada um deles associado a um cartão do ambiente computacional tangível. Por exemplo, em nossa proposta do Modo de Storyboard, a cena de um menino conversando com seus pais poderia ser retratada em um quadro com a imagem do menino, outro com a imagem da ação de falar e outros dois quadros com imagens de seu pai e sua mãe, respectivamente. Como cabe à professora de AEE estabelecer, de acordo com o estudo do caso de cada aluno, qual a representação mais adequada por meio de símbolos, essa mesma cena poderia ser representada por um único cartão, com a imagem de todos os personagens juntos e conversando. No Modo de Storyboard as crianças podem utilizar e escolher dentre os cartões na ordem que desejarem, criando a sua sequência da história que aparecerá na área de display.

\subsection{Modo de Storyboard - Versão $1.0^{5}$}

O Modo de Jogo e o Modo de Storyboard 1.0 foram desenvolvidos em HyperText Markup Language (HTML) e Javascript. Uma característica do software nessa fase do desenvolvimento é a não utilização de um banco de dados. A estratégia consistia em armazenar arquivos com figuras e sons em subdiretórios do disco rígido do computador a partir do qual o software era executado. Tais arquivos eram acessados por meio do código numérico de cada cartão RFID.

A Figura 8 apresenta um exemplo de utilização do Modo de Storyboard 1.0 e, ainda, como estão divididas as áreas da tela. $\mathrm{Na}$ área (a) é sempre apresentada a imagem referente ao último cartão lido. Em (b), a sequência dos cartões lidos é apresentada, limitada a 24 imagens. O item (c) apresenta uma área onde é possível configurar o ambiente; pode-se ativar ou desativar o som, e o ícone da "casa" apresenta a tela inicial do modo, porém não apaga as imagens dos quadros da área de storyboard. Para apagar os quadros dessa área, é necessária a leitura do cartão "Reiniciar". Para apagar um quadro na área de storyboard deve-se utilizar o cartão "Desfazer", que apaga sempre o último quadro com uma figura apresentada.

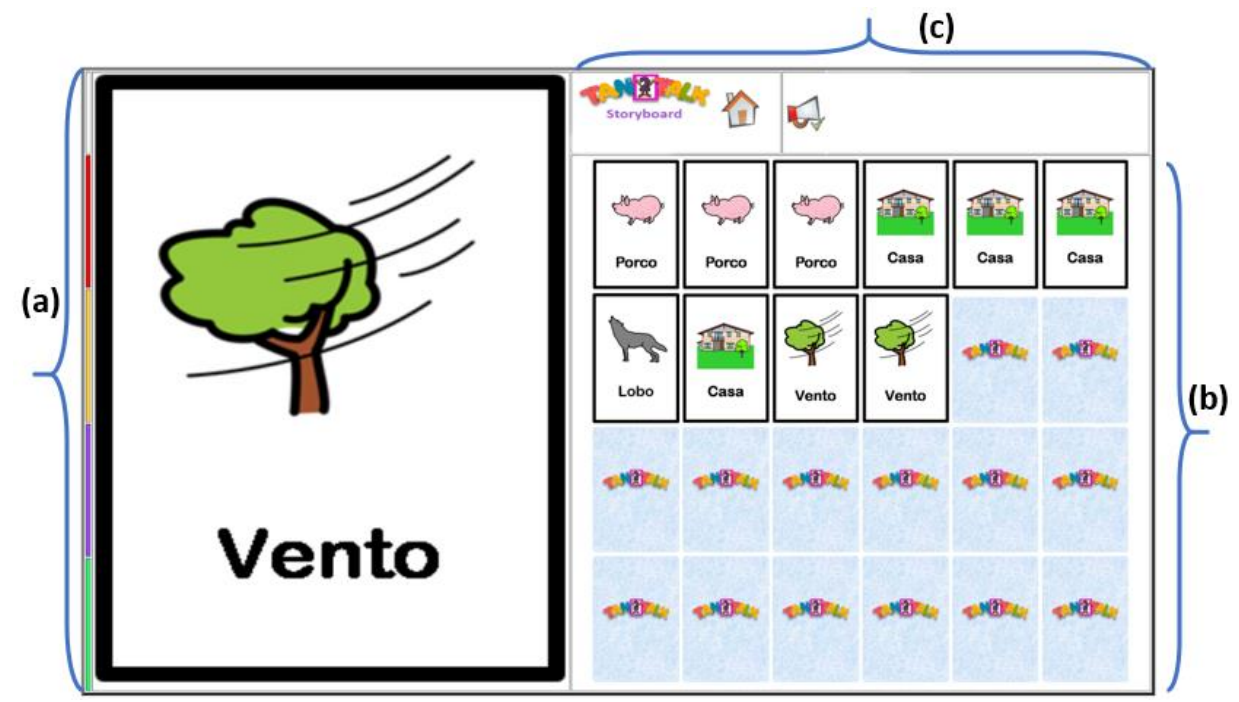

Figura 8. Tela do Modo de Storyboard 1.0, com exemplo de utilização: (a) imagem do último cartão lido; (b) área do storyboard; (c) área de configuração.

\footnotetext{
${ }^{5}$ Para efeitos de simplificação, no texto utilizaremos apenas a numeração para referirmos à versão do software, quando ela for relevante ao contexto.
} 
A Figura 9 apresenta o fluxograma para utilização da versão 1.0.



Figura 9. Fluxograma para utilização da versão 1.0 do Modo de Storyboard.

\subsection{Aplicação prática do Modo de Storyboard 1.0 - com professoras de educação especial que realizam o AEE}

Realizamos uma Oficina com professoras de educação especial, onde se utilizou o Modo de Storyboard 1.0. A atividade consistiu na elaboração, pelas participantes, de cenários onde a funcionalidade poderia ser aplicada junto aos alunos de modo a eliminar barreiras comunicacionais. As participantes trabalharam em duplas. Cada dupla foi convidada a propor uma atividade que poderia ser realizada em turmas comuns, ou no AEE, caso a professora de educação especial estivesse avaliando as possibilidades de eliminar barreiras comunicacionais com seu aluno. Cada proposta continha a metodologia, planejamento, objetivos e resultados esperados. As proponentes de cada atividade, além de elaborá-la também a aplicaram durante a mesma Oficina, onde as demais participantes realizavam as atividades que cabiam às crianças. Foram feitas três propostas de atividade.

\subsubsection{Proposta de Atividade 1: Desafio}

Duas participantes da Oficina propuseram uma atividade de desafio, cujo objetivo seria descobrir o que se estava comunicando, por meio, por exemplo, da narrativa de uma história ou fato, feita com os cartões de comunicação. No caso proposto, o tema tratado na atividade seria delimitado e combinado previamente entre todos os participantes; tal como, o tema poderia tratar de histórias infantis, situações do cotidiano etc. Entre os objetivos estavam a interação por pares (no caso de a atividade ser realizada em grupo) e, no contexto da CSA, a capacidade de estabelecer relações das imagens presentes nos cartões de comunicação com coisas ou situações do mundo e em seguida com alguma história conhecida, ampliando possibilidades de comunicação, cognitivas e de associação de ideias. Essa proposta se diferencia do Modo de Jogo de nosso ambiente inicial, pois nele não existe o fator competição e, ainda, por todas as figuras escolhidas estarem visíveis; no jogo, a projeção é apenas a da última figura lida. A Figura 10 apresenta momentos da aplicação da atividade. 

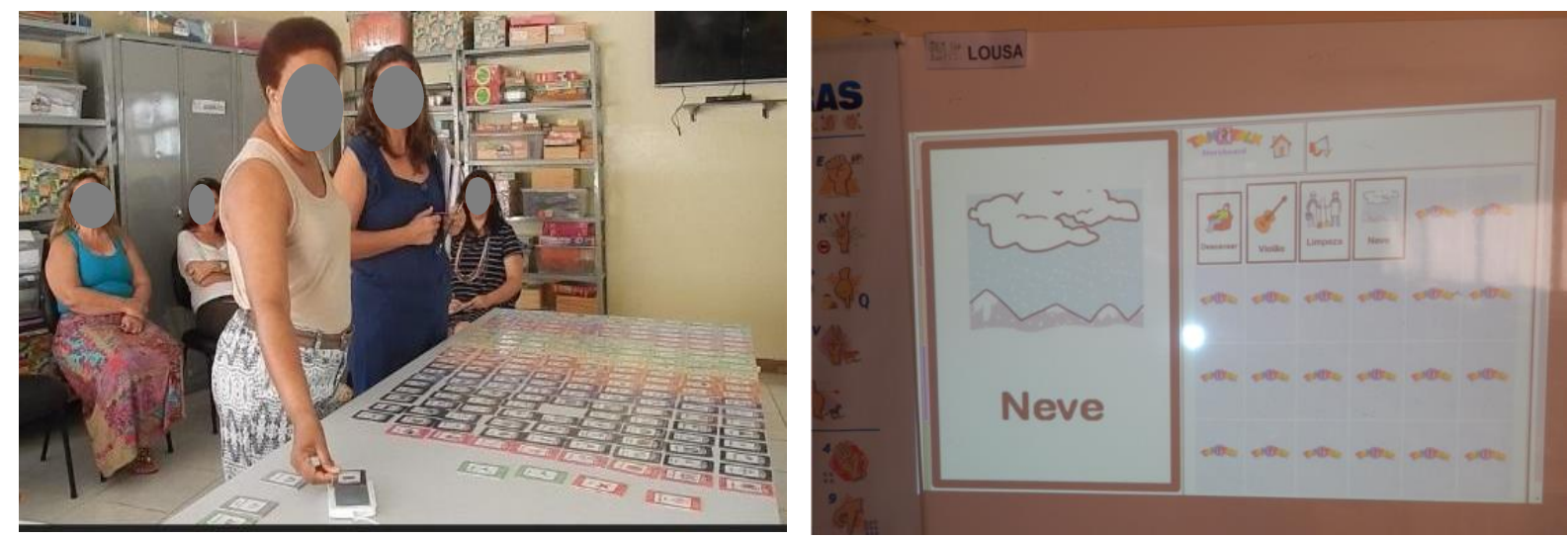

Figura 10. Proposta da atividade Desafio: à esquerda, professoras de educação especial realizando a dinâmica; à direita, storyboard (projetado no quadro da sala) com um momento da atividade.

\subsubsection{Proposta de Atividade 2: Contação de história}

Nessa proposta, as participantes criaram uma atividade em que a(s) criança(s) contariam ou recontariam uma história previamente narrada por alguma pessoa, seja de própria autoria dessa pessoa ou baseada em livros, vídeos, cantigas etc. Os objetivos cognitivos a serem trabalhados em sala de aula comum seriam a organização do pensamento, necessária à construção de narrativas, a atribuição de sentidos próprios para determinada história, considerando as possibilidades de cada aluno; no contexto da CSA, a capacidade de comunicar e expressar a história desejada. A contação da história pode ser feita individualmente ou em grupo. $\mathrm{Na}$ atividade, espera-se que a(s) criança(s) consiga(m) identificar os personagens e acontecimentos da história e tenha(m) a oportunidade de sequenciá-los com liberdade, empenhando-se para conferir a sua narrativa aspectos que caracterizem o início, o meio e o fim da história.

Durante a aplicação da atividade, as professoras participantes contavam trechos da história à medida que escolhiam os cartões relacionados. Do ponto de vista de pessoas que têm dificuldade para verbalizar, esse exercício pode estimular a fala e contribuir para que alunos com necessidades complexas de comunicação compartilhem suas percepções e pontos de vista com seus colegas e professoras, tendo as suas capacidades reconhecidas (Moita, Henrique, Candido, \& Medeiros, 2017). Frequentemente, estes alunos são considerados na escola como pessoas que não compreendem contextos, conteúdos e que não são capazes de criar seus próprios pensamentos, ideias, questionamentos e narrativas. Quando, por meio do trabalho de uma professora de AEE, são eliminadas barreiras na comunicação, contribui-se para que concepções equivocadas sobre o que é incluir sejam revistas e atualizadas. Tais atualizações abrem possibilidades para que professoras do AEE, do ensino comum, demais alunos e familiares, reconheçam as capacidades de todos e as limitações que são produzidas no meio em que vivem. Essas limitações costumam resultar em iniquidade, segregação e discriminação, mas que podem se converter em uma situação acessível e de comunicação, convivência, ensino e aprendizagem. A Figura 11 apresenta momentos da aplicação da atividade proposta pelas participantes. 

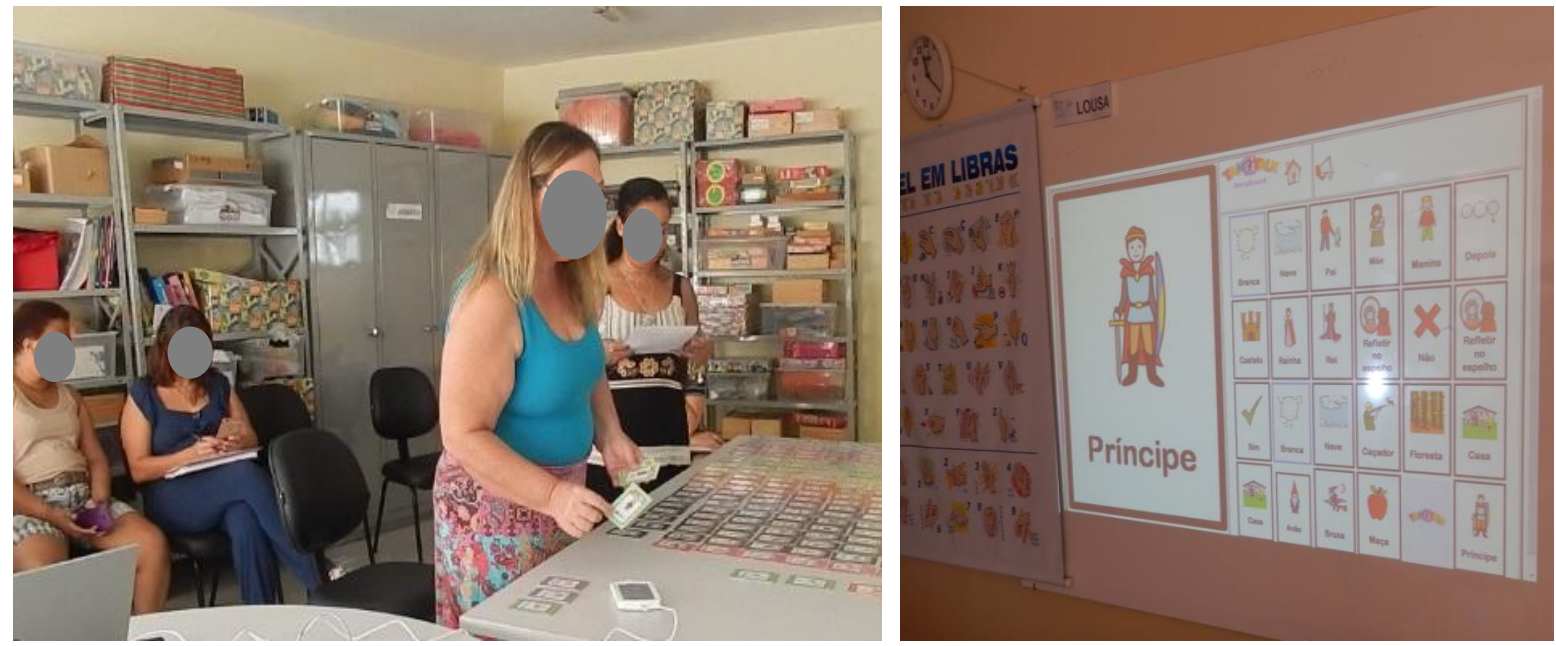

Figura 11. Proposta da atividade Contação de histórias: à esquerda, professoras realizando a dinâmica; à direita, storyboard (projetado no quadro da sala) com um momento da atividade.

\subsubsection{Proposta de Atividade 3: Sequência de ações}

Nessa atividade proposta, o objetivo é trabalhar com sequência de ações, seja ela uma situaçãoproblema, uma sequência didática, uma sequência de apoio à realização de atividades (por exemplo, ações a realizar após usar o banheiro) etc. A narrativa com os cartões de comunicação seria utilizada para dar comandos, de maneira a promover a associação, pela(s) criança(s), entre a ação e os símbolos dos cartões de comunicação. A Figura 12 apresenta um momento da realização da atividade pelas suas proponentes; no exemplo, à direita, a intenção era retratar as sequências de ações necessárias para que se "ande de motoca pelo jardim". Como não havia um cartão de comunicação que retratava a figura de uma motocicleta, as participantes decidiram utilizar a figura de uma "carruagem", de modo que as demais participantes fizessem associação com a "motoca". Tal decisão ocorreu pelo fato de que a dinâmica estava sendo realizada entre pessoas adultas com possibilidades de estabelecer relações entre o símbolo que representava a carruagem e a situação em que se "anda de motoca no jardim".

Neste momento, as participantes da Oficina se voltaram às possibilidades de articulação entre dois ou mais símbolos que pudessem satisfazer a necessidade de comunicação e de interação entre elas. Quando a comunicação acontece por meio da fala, a pessoa conta com a rapidez e variedade de vocábulos características deste canal que permite a interação. O mesmo não ocorre quando a comunicação se dá predominantemente por meio de símbolos gráficos, que são mais limitados. Ainda assim, a possibilidade de conectar um símbolo a outros disponíveis nas pranchas de cada aluno, permite a construção de uma série de combinações que podem satisfazer os anseios de comunicar em uma dada situação. Neste sentido, avaliamos como favorável a estratégia utilizada pelas participantes desta Oficina, quando combinaram símbolos com o propósito de se fazerem entender. Contudo, a professora de AEE deve decidir, de acordo com o estudo de caso do aluno que irá utilizar o recurso, se existe ou não a necessidade da criação de um cartão com um novo símbolo (como por exemplo, a figura direta de uma carruagem). Como subsídio para isso, existe o Modo de Gerenciamento do sistema, que auxilia a criação de cartões relacionados às mais diversas intenções comunicativas. Além disso, estes cartões podem conter conteúdos de diferentes disciplinas curriculares, por exemplo, matemática, ciências etc., ampliando as possibilidades de comunicação por meio deles. 

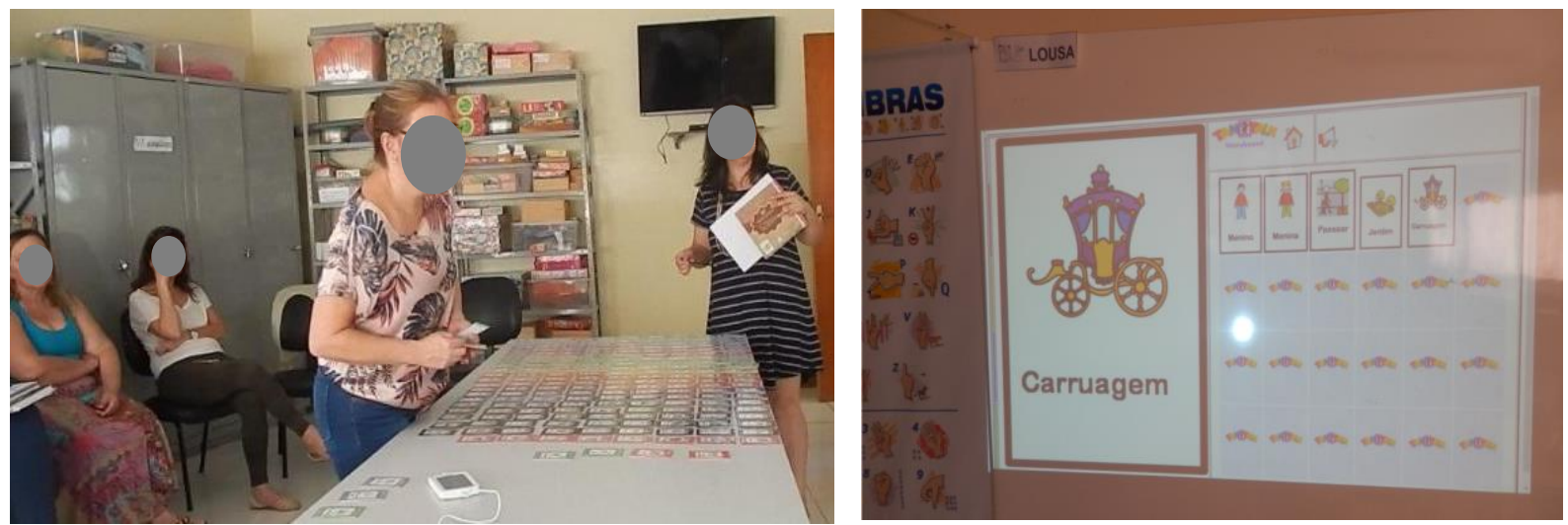

Figura 12. Proposta da atividade Sequência de ações: à esquerda, Professoras realizando a dinâmica; à direita, Storyboard (projetado no quadro da sala) com um momento da atividade.

Essas três situações propostas, elaboradas espontaneamente pelas professoras de educação especial participantes, são exemplos de atividades que podem ser realizadas usando o Modo de Storyboard, embora esta funcionalidade proporcione a utilização em vários outros contextos, sejam eles voltados à acessibilidade ou ao ensino de conteúdos nas salas inclusivas.

Por meio das propostas de atividades feitas pelas participantes foi possível observar certas características do Modo de Storyboard. Na proposta 1, a quantidade de quadros (24) disponíveis na área de storyboard foi insuficiente para contar a história com todos os detalhes que as participantes desejavam, sugerindo uma mudança no design. Ainda, as participantes atentaram também para a necessidade da inserção de sinais impressos da Língua Brasileira de Sinais (Libras) e a exibição de um vídeo com a sinalização em movimento.

No decorrer das Oficinas Participativas, as professoras de educação especial indicaram recursos, códigos, linguagens e línguas que tornariam o recurso que estava sendo produzido por todas, ainda mais acessível no campo da comunicação. Foi assim que inserimos no ambiente computacional tangível os símbolos da CSA, o Sistema Braille de Escrita e, por último, a Libras. Durante os diálogos construídos no trabalho colaborativo entre todas as participantes, as professoras expuseram as particularidades linguísticas e gramaticais da Libras que requerem ser devidamente trabalhadas nas turmas comuns que têm alunos considerados com surdez. A rede de ensino parceira neste estudo, propõe o trabalho concomitante com a Língua Portuguesa e a Libras realizado nas salas de aulas comuns por uma professora regente, que comumente desconhece a Libras, e uma professora de Libras. Estas professoras são orientadas para que todas as atividades escolares sejam planejadas, a fim de que contemplem as especificidades das duas línguas. Para a realização do Bilinguismo Concomitante (Lanuti, Baptista, \& Ramos, 2020), uma criação inédita dessa rede, as professoras do ensino comum orientam seus alunos, considerados ouvintes e com surdez, para que investiguem tanto a Língua Portuguesa como a Libras, e encontrem equivalências linguísticas e gramaticais entre elas, resultando no aprendizado de ambas por todos. Além disso, as professoras de educação especial mantêm-se focadas na identificação e na eliminação de barreiras comunicacionais, linguísticas e gramaticais produzidas na construção do Bilinguismo Concomitante. Assim, quando as professoras verificaram a necessidade de inserção da Libras no recurso computacional tangível que estavam produzindo, elas visualizaram a sua contribuição tanto no processo de aquisição da Libras e da Língua Portuguesa pelos alunos considerados ouvintes e com surdez, como no seu processo de aprimoramento que acontece ao longo das diferentes etapas da escolarização.

\subsection{Modo de Storyboard - Versão 2.0}

A versão 2.0 do Modo de Storyboard foi desenvolvida com base nas sugestões e observações realizadas na "Oficina Storyboard". Nesse ponto do desenvolvimento de nosso ambiente 
computacional tangível para apoio a comunicação, havíamos evoluído o software e o Modo de Gerenciamento já havia sido desenvolvido na linguagem Java ${ }^{\mathrm{TM}}$ para desktop, utilizando SQLite como Sistema de Gerenciamento de Banco de Dados. O Modo de Storyboard 2.0 foi desenvolvido utilizando essas mesmas características de banco de dados e linguagem de programação. Além disso, tanto o Modo de Gerenciamento, quanto o Modo de Storyboard passaram a ser acessados por meio de uma única aplicação (na versão anterior eles eram aplicações distintas, uma vez que a versão 1.0 do Modo de Storyboard era desenvolvida em HTML e Javascript).

O Modo de Storyboard 2.0 mantém as características já previamente existentes na sua versão 1.0 para vocalização dos cartões e apresentação das imagens correspondentes quando o cartão é aproximado ao leitor de RFID. Também apresenta a função "Reiniciar", para apagar todos os quadros da área de storyboard, e a função "Desfazer", que apaga sempre o último quadro com uma figura apresentada. Os eventos da funcionalidade (por exemplo, realizar upload, desabilitar áudio etc.) podem ser manipulados tanto selecionando seus respectivos botões (ou ícones) quanto por meio da utilização de Cartões de Eventos.

O Modo de Storyboard 2.0 permite que o usuário grave um áudio para a história. Assim, ao selecionar o botão do áudio (Figura 13.g) ou utilizar seu respectivo Cartão de Evento, o software iniciará o modo de gravação para que o usuário narre sua história. Além disso, o usuário pode associar um vídeo com a história sinalizada na Libras. Para isso deve ser feito o upload do vídeo desejado, utilizando o respectivo botão (Figura 13.f) ou seu respectivo Cartão de Evento.

$\mathrm{Na}$ versão 2.0 foi acrescentada a persistência dos dados, que possibilita que uma atividade seja retomada a partir do ponto em que foi encerrada (por exemplo, quando se continuará uma aula), uma vez que pode ser gravada em banco de dados. Assim, cada história deve ser associada a um cartão-tema, pois por meio dele é possível acessar a história gravada. Um mesmo cartãotema pode ser associado a um número ilimitado de histórias. Uma outra característica da versão 2.0 é que ela permite a impressão da área de storyboard.

Conforme observado na Seção 4.2, em uma das propostas de utilização da versão 1.0, a quantidade de quadros (24) disponíveis na área de storyboard foi insuficiente para contar a história com os detalhes desejados pelas participantes. Para lidar com a situação sem que o usuário tivesse que "rolar" a tela (pois já estaria usando as mãos para manipular os cartões), a versão 2.0 permite que a história criada no storyboard seja persistida em banco de dados. Assim, é possível criar várias partes da história e acessá-las quando desejado por meio da tabela com registros já existentes (Figura 13.e). Além disso, histórias com menos quadros provavelmente implicam em áudios e vídeos menores, que sobrecarregam menos o sistema operacional ao serem manipulados.

A Figura 13 apresenta um exemplo de utilização do Modo de Storyboard 2.0 e, ainda, como estão divididas as áreas da tela. $\mathrm{Na}$ área (a) é sempre apresentada a imagem referente ao último cartão lido. O item (b) apresenta uma área onde é possível configurar o ambiente para emitir ou não a vocalização relativa ao último cartão lido e exibir o mesmo conteúdo em Libras. Possui ainda um espaço para o nome da história. Em (c), a sequência dos cartões lidos é apresentada. O item (d) apresenta um conjunto de ferramentas para manipulação de registros, cujos ícones relacionados são habilitados ou desabilitados de acordo com a função sendo executada no momento (inclusão de nova história ou consulta/alteração/exclusão de uma história já existente). Em (e) é apresentada uma relação dos registros já existentes no banco de dados. Caso se deseje alterar ou excluir um deles é necessário selecioná-lo nessa tabela. O item (f) apresenta os botões com funcionalidades para manipulação de vídeo. Por fim, em (g) são apresentados os botões utilizados nas funcionalidades para manipulação de áudio. Todos os eventos da funcionalidade podem ser executados a partir de "Cartões de Eventos". 


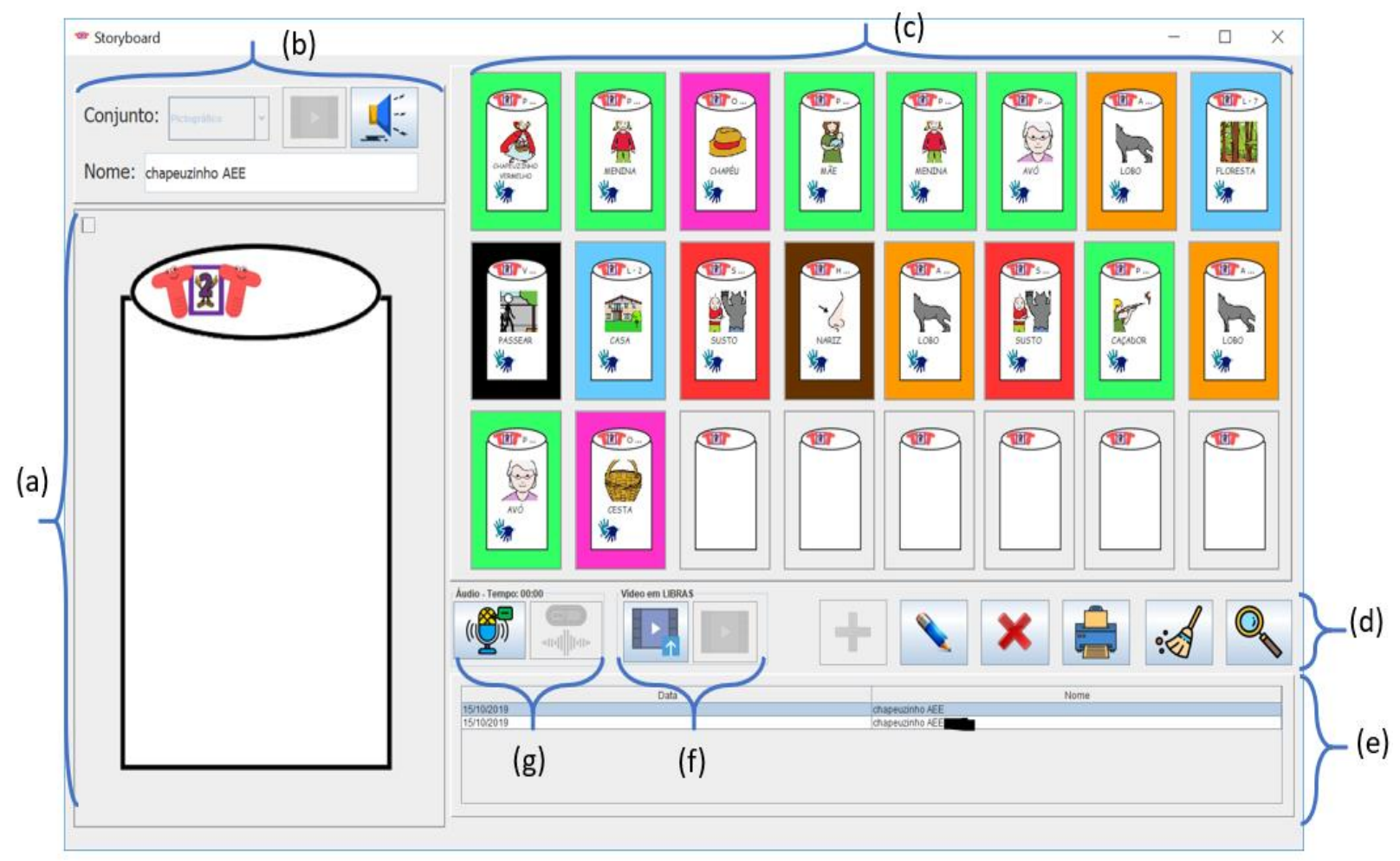

Figura 13. Tela do Modo de Storyboard 2.0, com exemplo de utilização: (a) Imagem do último cartão lido; (b) área de configuração; (c) área do storyboard; (d) ferramentas para manipulação de registros; (e) Registros já existentes no banco de dados; (f) e (g) área para gravação de áudio e upload de vídeo.

A Tabela 2 apresenta as principais características de cada uma das duas versões.

Tabela 2. Principais características das versões do Modo de Storyboard.

\begin{tabular}{|l|c|c|}
\hline \multicolumn{1}{|c|}{ Características } & Versão 1.0 & Versão 2.0 \\
\hline Linguagem de desenvolvimento & HTML e Javascript & Java \\
\hline Banco de dados & Não utiliza & Utiliza \\
\hline Manipulação da funcionalidade via cartões de eventos & Permite & Permite \\
\hline Habilitar/desabilitar sons dos cartões de comunicação & Permite & Permite \\
\hline $\begin{array}{l}\text { Estrutura de armazenamento de imagens e áudios dos } \\
\text { cartões }\end{array}$ & $\begin{array}{l}\text { Fisicamente armazenados } \\
\text { em estrutura de diretórios }\end{array}$ & $\begin{array}{c}\text { Persistidos em banco } \\
\text { de dados }\end{array}$ \\
\hline Integração com Modo de Gerenciamento & Não integrado & Integrado \\
\hline Persistência da narrativa & Não permite & Permite \\
\hline Libras & Não permite & Permite \\
\hline Armazenamento de áudio da narrativa & Não permite & Permite \\
\hline Armazenamento de vídeo (Libras) da narrativa & Não permite & Permite \\
\hline $\begin{array}{l}\text { Utilização de um mesmo cartão físico em diversos } \\
\text { modos de exibição (conjuntos) }\end{array}$ & Não permite & Permite \\
\hline $\begin{array}{l}\text { Edição/exclusão de narrativas previamente } \\
\text { armazenadas }\end{array}$ & Não aplica & Permite \\
\hline Impressão da narrativa & $\begin{array}{c}\text { Via opções disponíveis no } \\
\text { navegador }\end{array}$ & Permite \\
\hline
\end{tabular}

A Figura 14 apresenta o fluxograma para utilização da versão 2.0 (observe que, para efeitos de simplificação, encapsulamos os processos de manipulação de registros, de áudio e vídeo). 


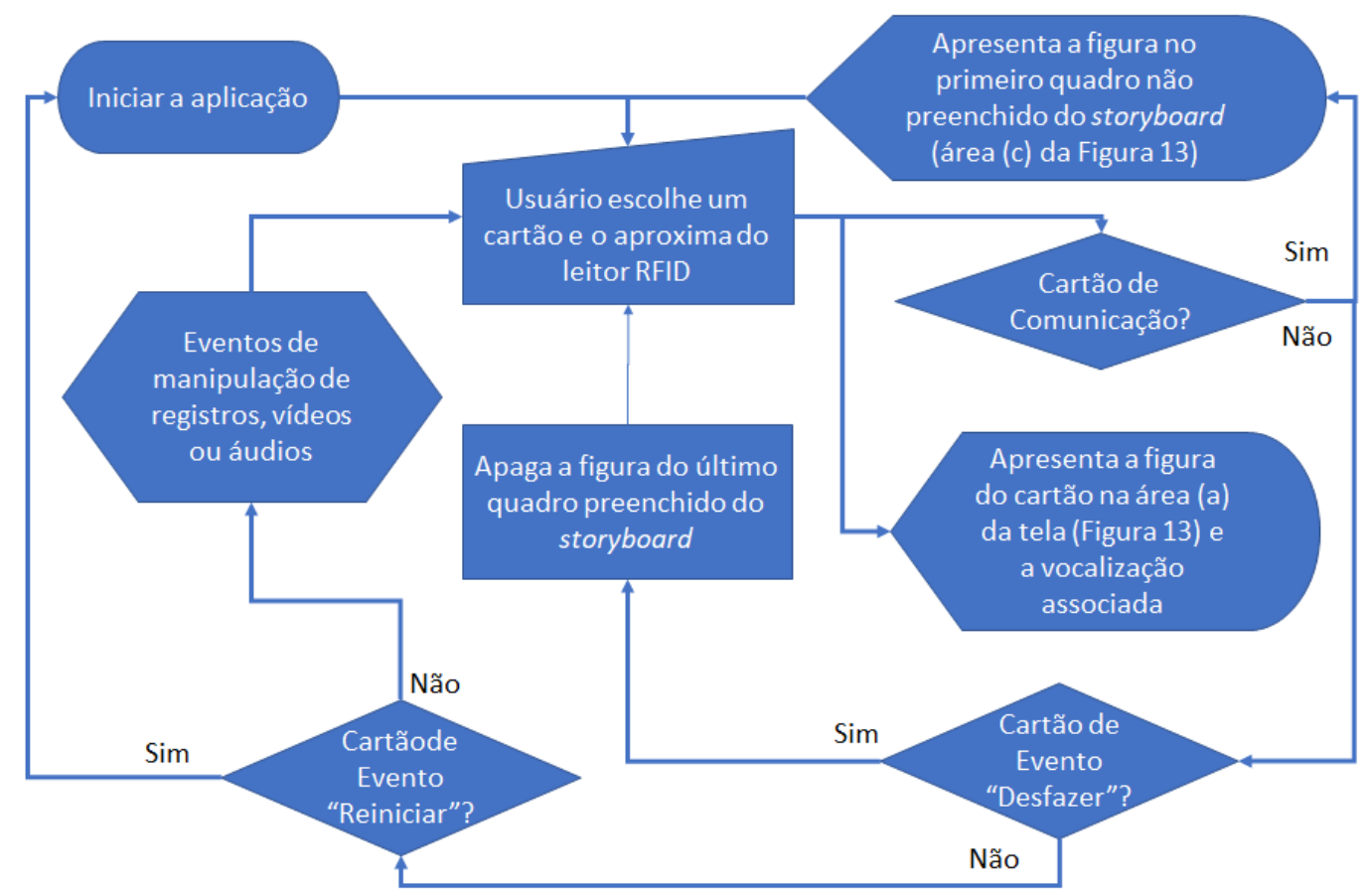

Figura 14. Fluxograma de utilização da versão 2.0 do Modo de Storyboard.

\subsection{Aplicação Prática do Modo de Storyboard 2.0 - com criança}

A versão 2.0 foi utilizada por um aluno no AEE, juntamente com sua professora. O aluno estava com 8 anos de idade, apresenta o Transtorno do Espectro do Autismo e possui dificuldades de se comunicar por meio da fala. $\mathrm{O}$ aluno está matriculado na rede parceira desde a Educação Infantil e, a partir de então, tem sido acompanhado pelo Programa de Educação Inclusiva.

\subsubsection{Planejamento}

Inicialmente, durante os primeiros 60 minutos de uma Oficina com as professoras, foi realizada a apresentação da nova versão do Modo de Storyboard. Em seguida, iniciou-se o planejamento (com duração de 30 minutos) de uma atividade a ser realizada com o aluno.

Nesse ponto é importante destacar que, apesar de o ambiente computacional tangível possuir originalmente 188 cartões de comunicação, fica a critério da professora de AEE decidir quais serão os utilizados na atividade a ser realizada com aluno(s), inclusive podendo criar outros cartões que julgar pertinentes. Assim, o número de cartões utilizados depende da avaliação feita pela professora de AEE que considera a adequação dos conteúdos representados nos cartões frente à situação de comunicação pretendida, e a qualidade da interação do aluno com os cartões, bem como suas possibilidades motoras para manuseá-los (dependendo do aluno, é necessário que os cartões estejam ao alcance das mãos, por exemplo).

Com base nesse contexto, as professoras decidiram que seria realizada a atividade de contação de história da "Chapeuzinho Vermelho" e que seus cartões representativos originalmente existentes estavam condizentes com o vocabulário do aluno, sendo necessário criar apenas um cartão por meio do Modo de Gerenciamento: o cartão de comunicação que representava a própria Chapeuzinho Vermelho. Dessa forma, as professoras de AEE decidiram utilizar 14 cartões de comunicação pertencentes ao vocabulário do aluno: "Passear", "Avó", "Menina", "Caçador", "Mãe", "Chapéu", "Cesta", "Visitar", "Floresta", "Casa", "Susto", "Nariz", "Lobo", "Chapeuzinho Vermelho". Para controle de eventos, foram utilizados os cartões "Reiniciar" e "Desfazer". Para a persistência, foi utilizado o cartão-tema da "Chapeuzinho Vermelho". 


\subsubsection{Aplicação}

A atividade consistiu inicialmente em a professora de AEE contar a história da "Chapeuzinho Vermelho" para o aluno, mostrando para ele os cartões de comunicação com as figuras, enquanto eram aproximados do leitor RFID. A Figura 15 apresenta um momento dessa Oficina.

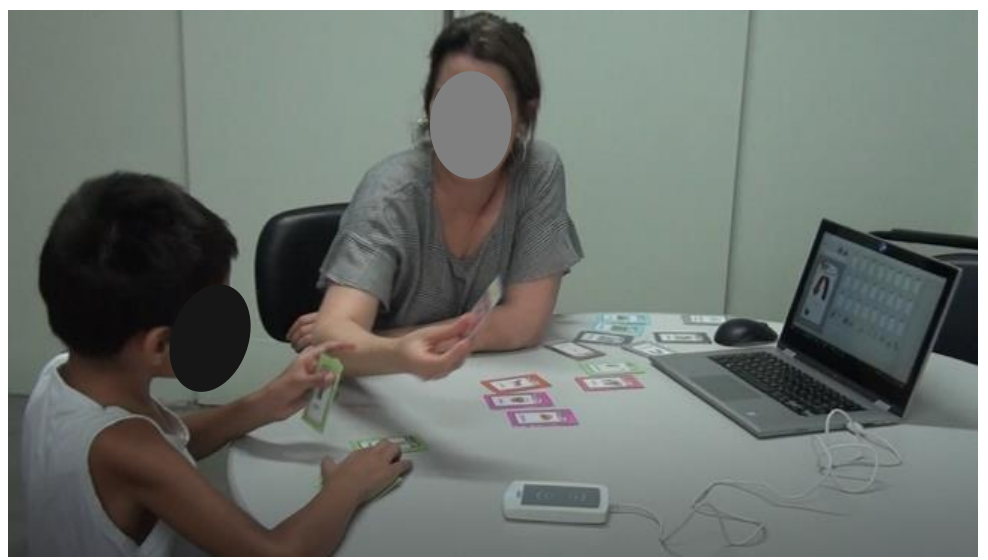

Figura 15. Um momento da Oficina com a criança.

A professora de AEE enfatizava para o aluno que ao aproximar o cartão do leitor, a imagem apareceria na tela. Para esse aluno, a professora optou por desabilitar o áudio de cada cartão de comunicação, isso porque, com aquele aluno especificamente, a voz humana parecia mais adequada à situação de comunicação. Em seguida, enquanto ela contava novamente a história, solicitava ao aluno para encontrar, dentre um conjunto de aproximadamente três cartões de comunicação, aquele que representava o que ela estava falando. Por exemplo, quando dizia que "Chapeuzinho era uma menina", solicitava ao aluno que pegasse o cartão da menina e aproximasse do leitor RFID. Ele não encontrou dificuldades para atender às solicitações da professora de AEE. A conduta da professora revelou aspectos da capacidade adaptativa do ambiente em uso. Após o término da história contada pela professora, ela salvou a sequência de símbolos gráficos produzida na interação com seu aluno.

Durante a atividade o aluno emitia sons de sílabas das imagens que estavam sendo escolhidas e demonstrava por meio de gestos que estava interagindo com a história: por exemplo, levava as mãos à boca quando o cartão escolhido era "Susto" ou sorria muito quando o cartão era "Avó". Conforme a professora foi usando as figuras para criar a história e à medida em que o aluno foi compreendendo-a, passou a demonstrar entusiasmo, principalmente quando percebeu que ao posicionar o cartão de comunicação sobre o leitor RFID, compunha-se a sua história na tela do computador com as mesmas imagens. Após a conclusão da atividade, o aluno optou pela sua continuidade, demonstrando o mesmo interesse inicial.

Com a nova versão do sistema, a professora pôde gravar a história dela e a criada pelo aluno. A professora ainda gravou um áudio contando a história e optou por não inserir um vídeo com a sinalização na Libras, pois este aluno não conhece esta língua. Durante a atividade, a professora usou o registro gravado anteriormente para recontar a história para o aluno. Além disso, ao final da atividade, ela gerou a impressão da história criada por ele, que a levou consigo. Essas particularidades não seriam possíveis na versão 1.0.

A expressão de alegria do aluno durante a realização da atividade demonstrou a importância de a tecnologia em forma computacional estar presente em todos os ambientes educacionais. Essa experiência é motivo de reflexão de quanto um ambiente desfavorecido de acessibilidade limita as possibilidades de desenvolvimento de um estudante. $\mathrm{O}$ fato de ver o aluno tendo autonomia intelectual, escolhendo as figuras de acordo com suas capacidades e interesses, corresponde ao 
que buscamos para o século XXI: uma ação pedagógica e educacional que inclua todos os alunos, proposta por Mantoan (2015).

\subsubsection{Resultados do uso}

As professoras que realizam o AEE na rede de ensino parceira verificam constantemente como as barreiras em estudo foram sendo eliminadas na escola e na família. Elas criam e formalizam registros que dão visibilidade ao trabalho que realizam e que possibilitam analisar as práticas da educação especial, favorecendo a atualização constante das mesmas.

As barreiras de comunicação, produzidas na situação de contação de história com o referido aluno, foram minimizadas com a utilização do novo ambiente computacional com recursos tangíveis. A Tabela 3 apresenta alguns comportamentos que a professora de AEE (que acompanhou o aluno na atividade) não observava, ou que eram manifestados pelo aluno de maneira muito discreta, nas situações de contação de histórias realizadas com recursos convencionais, como livros e fichas avulsas de CSA, e que foram observados no trabalho com o ambiente computacional tangível. Foram utilizadas três expressões como parâmetro para analisar os comportamentos do aluno, sendo elas: Pouco/pouca, Razoável e Muito(s)/muita(s).

Consideramos significativos os avanços nos comportamentos produzidos pelo aluno quando comparamos o cenário de contação de histórias com recursos convencionais e o cenário com recursos tangíveis. A situação analisada ilustra o entendimento da deficiência difundido pelo Modelo Social (Palacios, 2008), no qual a deficiência não está na pessoa, mas nas limitações do meio; no caso, nas limitações que impedem a efetiva comunicação entre os alunos considerados com necessidades complexas de comunicação e seus diferentes interlocutores. Quando o aluno viveu a situação de contação de história em um ambiente tangível mais acessível, suas possibilidades de interagir, comunicar, participar, criar, com leveza e alegria, foram ampliadas.

Outro aspecto que merece destaque, foi a adequada atuação da professora de AEE que se manteve focada no propósito de eliminar barreiras na comunicação.

Tabela 3. Comparação entre comportamentos apresentados pelo estudante nas situações de contação de histórias utilizando recursos convencionais ou computacionais tangíveis.

\begin{tabular}{|l|c|c|}
\hline O aluno apresentou na contação de história: & $\begin{array}{c}\text { Com recursos } \\
\text { convencionais (livros } \\
\text { e fichas avulsas de } \\
\text { CSA) }\end{array}$ & $\begin{array}{c}\text { Com recursos } \\
\text { computacionais } \\
\text { tangíveis }\end{array}$ \\
\hline Alegria & Razoável & Muita \\
\hline Interesse & Razoável & Muito \\
\hline Curiosidade & Razoável & Ruita \\
\hline Desejo de saber mais & Razoável & Muita \\
\hline Vontade de se manter na atividade & Razoável & Razoável \\
\hline Iniciativa de conhecer os recursos, olhando-os & Razoável & Muita \\
\hline Iniciativa de conhecer os recursos, pegando-os & Muita \\
\hline Expressões faciais & Muitas & Muitas \\
\hline $\begin{array}{l}\text { Expressões corporais (gestos, movimentos de } \\
\text { braços, pernas e cabeça) }\end{array}$ & Muitas & Muita \\
\hline Produção de sons & Muita & Muita \\
\hline Produção de palavras isoladas & Razoável & Muita \\
\hline Produção de palavras que têm sentido de frase & Muita & Muitos \\
\hline $\begin{array}{l}\text { Sinais de que estava construindo sentidos } \\
\text { próprios para o contexto }\end{array}$ & Razoável & \\
\hline
\end{tabular}




\section{Discussão e Conclusão}

Uma escola inclusiva é aquela que identifica barreiras e propõe ações para eliminá-las, pois barreiras dificultam ou impedem a participação efetiva e o desenvolvimento dos alunos. Nessa escola, cada um deve ter a oportunidade de se apropriar e de atualizar culturas, costumes, linguagens, línguas, códigos, conhecimentos, tecnologias e conteúdos. Para que os alunos exercitem e aprimorem suas reais capacidades, conforme interagem com objetos, pessoas, afetos e sensibilidades, as barreiras identificadas precisam deixar de ser produzidas na escola e na família. A educação especial, que se pauta na Perspectiva Inclusiva da Educação (Ministério da Educação, 2007), trabalha especificamente com barreiras que têm sido utilizadas para justificar a imposição da deficiência a certos alunos. Com isso, verificamos os benefícios dessa perspectiva nos serviços oferecidos pela educação especial (Ministério da Educação, 2007). Desvinculado do ensino de conteúdos curriculares, o AEE vem se mostrando uma força motriz na transformação das escolas comuns em espaços mais inclusivos, quando ele não se desvia do seu objetivo de identificar e propor ações que eliminem barreiras na escola e na família.

Neste estudo, descrevemos parte de um percurso no qual eliminamos barreiras comunicacionais produzidas na escola comum. Participaram ativamente deste percurso: pesquisadoras, com formação no campo da Computação, professoras da Educação Especial, atuantes em uma rede de ensino pública e municipal, e duas assessoras, sendo uma fonoaudióloga com formação em CSA, e outra fonoaudióloga, professora doutora em Educação, com formação na Educação Bilíngue (Língua Portuguesa e Libras), em inclusão no ensino comum e na educação especial.

Em nossos estudos temos utilizado um ambiente computacional tangível para apoio à comunicação, concebido com base na proposta do Design Universal, isto é, de maneira a ser acessível à maior extensão possível de pessoas (não apenas àquelas consideradas com alguma deficiência). Identificamos no design para todos um campo vasto de possibilidades tecnológicas e informacionais, que ao serem articuladas às especificidades de cada situação de interação e de comunicação inacessível das escolas comuns, contribuíram efetivamente para a construção de uma escola para todos. Isto porque a situação de comunicação antes inacessível converteu-se em uma situação acessível.

O ambiente computacional, inicialmente planejado para ser utilizado sob a forma de um jogo de adivinhações, possuía potencial para uso em outros contextos, especialmente para apoio à comunicação e interação entre alunos que encontram dificuldades para se fazer entender pela fala e quaisquer outros interlocutores da escola comum e da família. Neste trabalho, descrevemos como conduzimos, de forma participativa, o redesign do ambiente inicial (Moreira \& Baranauskas, 2016), envolvendo professoras de AEE e sua prática cotidiana. As atividades foram realizadas no formato de Oficinas para explorar outras formas de uso do ambiente no cotidiano escolar. Com base nos resultados iniciais das Oficinas, implementamos o Modo de Storyboard, para trabalhar narrativa com crianças.

Em nosso ambiente, o computador serve como um meio para a execução da aplicação permitindo o gerenciamento dos cartões e execução das funcionalidades Jogo e Storyboard. Ele (o computador), portanto, não é o protagonista no ambiente criado, se olharmos para a perspectiva do design desse ambiente para a interação das crianças e das professoras no espaço educativo inclusivo; sua 'invisibilidade' é desejável, nesse caso, para dar saliência à tangibilidade dos cartões na criação de narrativa.

A versão inicial do Modo de Storyboard foi apresentada em um trabalho anterior (Moreira et al., 2018). Neste artigo, estendemos aquele trabalho, mostrando a implementação da nova versão do software, que inclui os requisitos apontados como limitações em sua versão anterior. Este 
trabalho contribuiu ainda com a aplicação prática do sistema no contexto de uso por uma professora e uma criança que possui dificuldades para se comunicar por meio da fala.

Resultados apontaram que a criança ficou muito entusiasmada ao usar os cartões, inclusive, quando apontava para eles, emitia sons de sílabas referentes às imagens nos cartões, o que revelou que a atividade desencadeou uma maior motivação e estimulação para o desenvolvimento da linguagem oral. A utilização da figura como apoio à oralidade, garantindo a compreensão da mensagem pelo outro, estimula a possibilidade de um maior desenvolvimento dessa oralidade. Ainda, a rede municipal de ensino que participou da construção deste estudo considera de fundamental importância o trabalho com histórias infantis.

Neste sentido, contar com recursos computacionais tangíveis, que se somem à CSA trabalhada nas escolas comuns desta rede desde 2009, à Língua Brasileira de Sinais (Libras) presente na Educação Bilíngue e inclusiva desde 2006, foi algo bem recebido pelas profissionais da educação. Recursos oriundos da Computação, quando são produzidos e utilizados no campo educacional, devem se alinhar à concepção de desenvolvimento humano, ensino e aprendizagem defendida pelos profissionais das redes de ensino. Assim, a possibilidade de combinar e criar com liberdade, por meio de recursos computacionais tangíveis, potencializada na parceria que se consolidou entre pesquisadores da Computação e as professoras da rede, fortaleceu o trabalho voltado à acessibilidade comunicacional já existente nas escolas comuns do município.

Destacamos que a interação entre Computação e Educação foi essencial para que o ambiente computacional tangível fosse criado e produzido, a partir de situações reais nas quais se identificam impedimentos na comunicação entre alunos considerados com necessidades complexas de comunicação, colegas, professores e familiares. O trabalho dinâmico, colaborativo e participativo de todos os interessados neste estudo, compôs um ambiente aplicável a situações de comunicação, com traços universais caracterizados pela presença de figuras da CSA, do Sistema Braille de Escrita, da Libras e da Língua Portuguesa falada e escrita, e com traços singulares coletados no estudo de cada situação de comunicação antes inacessível, realizado pelas professoras de educação especial. Ressaltamos que em cada situação de comunicação, os interlocutores envolvidos agem de maneira singular e imprevisível quando utilizam o ambiente que criamos, assim como ocorre com aqueles que se comunicam predominantemente pela fala. Assim, neste trabalho, promovemos um encontro entre o universal, oriundo das várias aplicações possíveis do ambiente proposto, e o singular, que se manifesta em cada experiência de comunicação vivida por alunos considerados com necessidades complexas de comunicação, seus colegas e professores, pertencentes a escolas públicas comuns.

Consideramos que as situações escolares e extraescolares, caracterizadas por impedimentos na comunicação que separam, afastam e impedem a convivência livre e criativa entre alunos e professores, são as que mais têm prejudicado o pleno desenvolvimento e a inserção social de alunos que têm direito aos serviços da educação especial no Brasil. Com o uso da tecnologia, podemos observar avanços no sentido de contribuir para que a escola, a família e a sociedade passem a identificar a deficiência nas situações de comunicação, levando-nos a considerar que a imposição desta deficiência sobre modos particulares de comunicar e de vir a ser de certos alunos, tem camuflado a necessidade e a urgência de mudanças na escola e na sociedade, a fim de que se transformem e sejam inclusivas. Neste sentido, propomos que passemos a considerar a deficiência de cada situação de comunicação inacessível, que pode se tornar acessível, e que reconheçamos todas as formas de interagir, comunicar, criar e vir a ser de cada um dos nossos alunos, legitimando-as.

Por fim, propomos o fortalecimento de parcerias entre diferentes áreas do conhecimento na criação, produção e no aperfeiçoamento de ambientes, artefatos e recursos que tenham potencial para eliminar as tantas barreiras de comunicação, que diariamente são produzidas nas escolas comuns que pretendem ser mais acessíveis e inclusivas. 
O próximo passo em nosso trabalho envolverá a utilização do novo sistema em Oficinas com crianças e suas professoras em sala de aula na rede parceira, seguindo o mesmo rigor aqui apresentado na coleta dos dados, análise e discussão dos resultados. A pesquisadora da Computação disponibilizou o conjunto de cartões produzidos neste estudo à rede de ensino, a fim de que sejam frequentemente utilizados e atualizados de acordo com as necessidades de transformação de cada situação comunicacional identificada pelas professoras de AEE. Com isso, ampliam-se as possibilidades de novos estudos na área.

\section{Agradecimentos}

Apoiaram este trabalho: Instituto Federal de São Paulo, CNPq (\#306272/2017-2), FAPESP (\#2015/16528-0), Instituto de Computação, Divisão de Educação Infantil e Complementar, Núcleo de Informática Aplicada à Educação, Faculdade de Educação e Grupo Gestor de Benefícios Sociais da UNICAMP.

Agradecemos especialmente à Secretaria de Educação do município de Amparo/SP.

\section{Referências}

Alessandrini, A., Cappelletti, A., \& Zancanaro, M. (2014). Audio-augmented paper for therapy and educational intervention for children with autistic spectrum disorder. International Journal of Human Computer Studies, 72(4), 422-430. doi: 10.1016/j.ijhcs.2013.12.001

Amparo. (2016). Programa de Educação Inclusiva : "A educação tem muitas faces - Educando e aprendendo na diversidade” (pp. 1-10). Secretaria Municipal de Educação. Disponível em: http://www.educaon.com.br/amp. Acessado em 12 mar. 2021.

ARASAAC. (2018). Portal Aragonês de Comunicação Aumentativa e Alternativa. Disponível em: http://www.arasaac.org. Acessado em: 31 jan. 2015.

ASHA. (2016). American Speech-Language-Hearing Association. Disponível em: www.asha.org. Acessado em: 4 fev. 2016.

Baranauskas, M Cecília C, \& Posada, J. E. G. (2017). Tangible and Shared Storytelling: Searching for the Social Dimension of Constructionism. Interaction Design and Children Conference, 193-203. Stanford, CA, USA. doi: 10.1145/3078072.3079743

Baranauskas, Maria Cecília Calani. (2013). O Modelo Semio-participativo de Design. In Codesign de Redes Digitais: Tecnologia e Educação a Serviço da Inclusão Social (pp. 3866). Porto Alegre: Editora Penso.

Burton, S., \& Matthewson, L. (2015). Targeted Construction Storyboards in Semantic Fieldwork. In M. R. Bochnak \& L. Matthewson (Eds.), Methodologies in Semantic Fieldwork (pp. 135156). Oxford University Press. doi: 10.1093/acprof:oso/9780190212339.003.0006

Casa Civil. Decreto $N^{o}$ 6.949. Promulga a Convenção Internacional sobre os Direitos das Pessoas com Deficiência e seu Protocolo Facultativo, assinados em Nova York, em 30 de março de 2007. (2009). Brasil. Disponível em: http://www.planalto.gov.br/ccivil 03/ ato2007-2010/2009/decreto/d6949.htm. Acessado em 12 mar. 2021.

Casa Civil. Decreto $N^{o}$ 7.611. Dispõe sobre a educação especial, o atendimento educacional especializado e dá outras providências. (2011). Brasil. Disponível em: http://www.planalto.gov.br/ccivil_03/ato2011-2014/2011/decreto/d7611.htm. Acessado em 12 mar. 2021. 
Chun, R. Y. S. (2009). Comunicação suplementar e/ou alternativa: abrangência e peculiaridades dos termos e conceitos em uso no Brasil. Pró-Fono Revista de Atualização Científica, 21(1), 69-74. doi: 10.1590/S0104-56872009000100012

Garzotto, F., \& Bordogna, M. (2010). Paper-based Multimedia Interaction as Learning Tool for Disabled Children. Interaction Design and Children Conference, 79-89. Barcelona, Spain. [GS Search]

Hengeveld, B., Hummels, C., Balkom, H. Van, Voort, R., \& Moor, J. De. (2013). Wrapping Up LinguaBytes, For Now. International Conference on Tangible, Embedded and Embodied Interaction, 237-244. Barcelona, Spain. [GS Search]

Kensing, F., \& Blomberg, J. (1998). Participatory Design: Issues and Concerns. Computer Supported Cooperative Work (CSCW), 7(3), 167-185. doi: 10.1023/A:1008689307411

Lanuti, J. E. de O. E., Baptista, M. I. S. D., \& Ramos, E. de S. (2020). A diferença de Deleuze na pesquisa em educação: experiências dos pesquisadores do LEPED. Revista Ibero-Americana de Estudos Em Educação, 15(3), 1167-1180. doi: 10.21723/riaee.v15i3.12627

Mantoan, M. T. E. (2003). Inclusão escolar: O que é? Como fazer? São Paulo: Editora Moderna. [GS Search]

Mantoan, M. T. E. (2015). Diferenciar para incluir ou para excluir? Por uma pedagogia da diferença. Educação Inclusiva. Revista Da Pró Inclusão/Associação Nacional Dos Docentes de Educação Especial, 6, 11-14. [GS Search]

Mayer-Johnson Inc. (2002). Boardmaker. Solana Beach, California.

Ministério da Educação. Política Nacional de Educação Especial na Perspectiva da Educação Inclusiva. (2007). Brasil. Disponível em: http://portal.mec.gov.br/arquivos/pdf/politicaeducespecial.pdf. Acessado em 12 mar. 2021.

Moita, F., Henrique, L., Candido, V., \& Medeiros, F. M. (2017). Design e desenvolvimento de um game assistivo para autistas. XXVIII Simpósio Brasileiro de Informática Na Educação, 1057-1066. doi: $10.5753 /$ cbie.sbie.2017.1057

Moreira, E. A., \& Baranauskas, M. C. C. (2016). Investigando processos de comunicação alternativa via tecnologia tangível: um estudo exploratório. XXVII Simpósio Brasileiro de Informática Na Educação, 856-865. doi: 10.5753/cbie.sbie.2016.856

Moreira, E. A., \& Baranauskas, M. C. C. (2018). Experimentando e Delineando um Vocabulário para um Ambiente Tangível de Apoio à Comunicação Alternativa e Aumentativa. 17th Brazilian Symposium on Human Factors in Computing Systems. Belém, Pará. doi: $\underline{10.1145 / 3274192.3274216}$

Moreira, E. A., Ramos, E. D. S., Wolff, L., Bortolini, C. D. T., Benedetti, M. L. P., Oliveira, M. R. P. De, ... Bruschini, M. do C. B. (2018). Explorando a Utilização de Storyboard em um Ambiente Tangível de Apoio à Comunicação Alternativa e Aumentativa. XXIX Simpósio Brasileiro de Informática $\mathrm{Na}$ Educação. Fortaleza, $\mathrm{CE}$, Brasil. doi: $\underline{10.5753 / \text { cbie.sbie.2018.1083 }}$

Palacios, A. (2008). El modelo social de discapacidad: orígenes, caracterización y plasmación en la Convención Internacional sobre los Derechos de las Personas con Discapacidad. In Madrid Cinca. [GS Search]

Pandey, S., \& Srivastava, S. (2011). SpellBound: A tangible spelling aid for the dyslexic child. ACM International Conference Proceeding Series, 101-104. doi: 10.1145/2407796.2407813

Sonza, A. P., Kade, A., Façanha, A., Resende, A. L. A., Nascimento, G. S. do, Rosito, M. C., ... Fernandes, W. L. (2013). Acessibilidade e Tecnologia Assistiva - Pensando a inclusão 
sociodigital de pessoas com necessidades especiais. Bento Gonçalves, RS: Secretaria de Educação Profissional e Tecnológica - SETEC/MEC. Disponível em: https://drive.google.com/file/d/1wtpwN4govndQFhGOYwtHnCVZ3bCegrJ0/view.

Acessado em 12 mar. 2021.

Story, M. F., Mueller, J. L., \& Mace, R. L. (1998). The Universal Design File: Designing for People of All Ages and Abilities. Revised Edition. (5). [GS Search]

Tenor, A. C., \& Deliberato, D. (2004). Estratégias de mediação para o conto e reconto de histórias para alunos surdos. Revista Educação Especial, 29(56), 681-694. doi: $\underline{10.5902 / 1984686 \times 17172}$

Ullmer, B., \& Ishii, H. (2000). Emerging frameworks for tangible user interfaces. IBM Systems Journal, 39(3.4), 915-931. doi: 10.1147/sj.393.0915 